\title{
Birthright citizenship: reflexiones en torno a familias, menores y la nacionalidad por derecho de nacimiento en los Estados Unidos de América
}

\author{
Birthright Citizenship: Insights about Families, \\ Minors and Birthright Nationality \\ in the United States of America
}

\section{Birthright citizenship: réflexions sur les familles, les mineurs et la nationalité par naissance aux Etats-Unis d'Amérique}

\section{Nuria González Martín*}

SUMARIO: I. Introducción. II. Birthright citizenship en los Estados Unidos: ius soli. III. Minoridad en estado de vulnerabilidad. IV. Conclusiones. V. Bibliografía.

\footnotetext{
* Universidad Nacional Autónoma de México, México; ORCID ID: https://orcid.org/00 00-0001-5139-0772,nuria.gonzalez68@gmail.com.
} 
RESUMEN: El presente artículo trata sobre la nacionalidad por derecho de nacimiento en los Estados Unidos de América y expone cómo esta nación es uno de los 34 países que otorgan la nacionalidad por ius soli; es decir, por el hecho de haber nacido en territorio nacional, tal y como se deriva de la Decimocuarta Enmienda constitucional norteamericana, y en este caso, una adquisición de la nacionalidad sin restricciones a pesar de que la tendencia actual es hacia la imposición de condiciones para adquirir la nacionalidad mediante ius soli. Un ejemplo de esta tendencia, plasmada en iniciativas de leyes, la encontramos en la política más reciente estadounidense, a través de la Birthright Citizenship Act (H. R. 140), de 2019. Esta iniciativa de ley de ciudadanía por derecho de nacimiento, negaría la ciudadanía a los niños nacidos en los Estados Unidos, a menos que uno de los padres del niño sea ciudadano, residente legal permanente o residente legal que preste servicio militar en los Estados Unidos. Dicha ley violaría el texto de la mencionada decimocuarta enmienda constitucional, así como leyes secundarias. Como parte de la casuística expuesta, en el mismo tenor, en el artículo se analiza el fenómeno de los bebés anclas y el caso de las familias separadas en la frontera México-Estados Unidos bajo la denominada doctrina de "tolerancia cero", por la cual todo inmigrante indocumentado se considera un delincuente y se le procesa judicialmente como tal, aunque no tenga antecedentes penales; "motivo" por el cual los niños no pueden seguir junto a sus padres y son separados, con un resultado para los padres que suele ser la deportación. La práctica de separar a los menores de sus familiares no respondió nunca a ninguna ley, y de ahí la orden ejecutiva del 20 de junio de 2018 que paralizó tal medida.

Palabras clave: nacionalidad por derecho de nacimiento, ius soli, ius sanguinis, tolerancia cero, menores migrantes no acompañados, familias separadas, México, Estados Unidos de América.

ABSTRACT: This paper deals with birthright citizenship in the United States of America and explains how this nation is one of the 34 countries that grant nationality by Ius Soli, that is, by the fact of being born in national territory, as derived from the fourteenth American constitutional amendment, and in this case, an unrestricted acquisition of nationality, although it should be noted that the current trend is towards the imposition of conditions to acquire nationality through Ius Soli. An example of this trend, reflected in legislative initiatives, can be found in the most recent US policy, through the 2019 Birthright Citizenship Act (HR140). This birthright citizenship law initiative would deny the citizenship to children born in the United States unless the child's parent is a citizen of the United States or is a lawful permanent resident or legal resident serving in the United States. This law would violate the text of the aforementioned fourteenth constitutional amendment, as well as secondary laws. By the same token, ass part of the casuistry presented, there is the phenomenon of anchor babies and the case of separated families at the United States-Mexico border which are analyzed under the so-called "zero tolerance" doctrine by which all undocumented immigrants are considered as criminals and prosecuted as such, even if there is no criminal record, and for this "reason" children cannot remain with their parents and are separated. The end result for the parents is usually deportation. The reality is that this practice of separating minors from their relatives never responded to any law and hence the executive order of June 20, 2018 that paralyzed such measure.

Key words: birthright citizenship, ius soli, ius sanguinis, zero tolerance, unaccompanied minors, separated families, Mexico, United State of America. 
RÉSUMÉ: Cette contribution traite la nationalité par droit de naissance aux États-Unis d'Amérique et explique comment cette nation est l'un des 34 pays qui accordent la nationalité à Ius Soli, c'est-à-dire par le fait d'être né sur le territoire national, come dérivé du quatorzième amendement constitutionnel américain, et dans ce cas, une acquisition sans restriction de la nationalité, même s'il convient de noter que la tendance actuelle est à l'imposition de conditions pour acquérir la nationalité par le biais de Ius Soli. Un exemple de cette tendance, reflétée dans les initiatives législatives, peut être trouvé dans la politique américaine la plus récente, à travers la loi Birthright Citizenship Act 2019 (HR140). Cette initiative de loi sur la citoyenneté du droit de naissance refuserait la citoyenneté aux enfants nés aux États-Unis à moins que le parent de l'enfant ne soit citoyen américain ou résident permanent légal ou résident légal servant aux États-Unis. Cette loi violerait le texte de la quatorzième modification constitutionnelle susmentionnée, ainsi que les lois secondaires. Dans le cadre de la casuistique présentée, dans la même veine, le phénomène des bébés ancres et le cas des familles séparées à la frontière américano-mexicaine sont analysés sous la doctrine dite de la «tolérance zéro» selon laquelle tous les immigrants sans papiers sont eux -même des criminels et sont poursuivis en tant que tel, même s'ils n'ont pas de casier judiciaire, et pour cette «raison», les enfants ne peuvent pas rester avec leurs parents et sont séparés, ce qui résulte à la déportation des parents. La réalité est que cette pratique de séparation des mineurs de leurs proches n'a jamais répondu à aucune loi et donc au décret du 20 juin 2018 qui a paralysé une telle mesure.

Mots-clés: citoyenneté de naissance, ius soli, ius sanguinis, tolérance zéro, mineurs non accompagnés, familles séparées, Mexique, États-Unis d’Amérique. 
Esta revista forma parte del acervo de la Biblioteca Jurídica Virtual del Instituto de Investigaciones Jurídicas de la UNAM

\section{INTRODUCCIÓN}

El derecho internacional privado (DIPr) actual presenta una nueva terminología globalizadora familiar internacional, transfronteriza, transnacional y migratoria.

Hablamos de una familia que no puede ser entendida sólo dentro de una frontera nacional, en donde se visualizan diferentes tipos de familias o modelos familiares y en donde la globalización les afecta de manera contundente. ${ }^{1}$ Entre estas categorías tenemos:

- Familia internacional, es decir, aquella en la que cada cónyuge, compañero/a, puede nacer y crecer en diferentes Estados o naciones.

- Familias transfronterizas, aquellas que se mueven, en conjunto o en parte, a otro Estado o nación.

- Familias transnacionales, como puede ser aquella producto de la reproducción asistida, creadas por los gametos o los servicios de embarazo en el extranjero.

- Familias productos de la migración, en las que uno o más miembros de la familia son atendidos por un trabajador migrante remunerado, aunque el término es más extenso porque las migraciones toman formas y categorías muy diversas. Entonces, traigamos a colación la familia migrante que busca, simple y llanamente, mejores condiciones de vida, la familia refugiada o la que busca asilo — accidental, estrategia temporal o forzada_- ${ }^{2}$ Éstas últimas especialmente castigadas en

1 El derecho de familia internacional y transnacional ha sido un campo de estudio en desarrollo y un área creciente de práctica legal en los últimos años. Para ver toda esta temática crucial, recomendamos la lectura de Douglas, G. et al. (eds.), International and National Perspectives on Child and Family Law. Essays in Honour of Nigel Lowe, Cambridge, Intersentia, 2018; Gaudement-Tallon, $H$., "Individualisme et mondialisation: aspects de droit international privé de la famille", A Commitment to Private International Law. Essays in honour of Hans van Loon/Un engagement au service du Droit international privé. Mélanges en l'honneur de Hans van Loon, CambridgeAmberes-Portland, Intersentia, 2013, pp. 181-194, entre otros.

2 González Martín, Nuria, "Globalización familiar: nuevas estructuras para su estudio", Libro Homenaje al Profesor Eugenio Hernández-Bretón, Caracas, Academia de Ciencias Políticas y Sociales, 2019, t. I, pp. 649-678. 
fronteras como la de México y Estados Unidos, y en las que hacemos especial hincapié en esta contribución.

Por supuesto, la numeración arriba anotada no se acota con esas cuatro categorías generales, basta con dar un vistazo a nuestro alrededor y percatarse, casi de inmediato, de que un elemento de extranjería está siempre presente, y de ahí una diferente interpretación, desde el DIPr, de lo que representa el concepto de familia y, por ende, los diferentes modelos familiares. ${ }^{3}$

Como podemos ver, actualmente es importante visualizar la interrelación indiscutible entre la globalización, las fronteras, las familias y la ley. Para ello, es imprescindible considerar, asimismo, el papel de las leyes internacionales, multinacionales y religiosas en la configuración de las vidas de millones de familias que se ven afectadas tanto por las oportunidades como por los desafíos creados por la globalización y la continua resistencia de las fronteras nacionales y culturales. ${ }^{4}$

En esa misma tónica, el derecho a la nacionalidad del país dónde se nació, es decir, el denominado ius soli, se torna en una suerte vigente que protege al individuo per se, pero en donde las restricciones van en incremento.

Con este prolegómeno, donde la variedad y movilidad familiar se hacen patentes, queremos dar entrada al tema que traemos a colación en esta ocasión: el de la nacionalidad por derecho de nacimiento en los Estados Unidos de América, y así visualizar perspectivas y consideraciones actuales. Para ello, el lector tendrá la oportunidad de leer el panorama jurídico que sustenta dicho derecho de nacionalidad en los Estados Unidos, y en referencia, aunque sea tangencial, el estatus actual de la comunidad internacional al asumir ius soli o ius sanguinis para la determinación de la nacionalidad (II).

3 Muir Watt, Horatia, "Les modèles familiaux à l'épreuve de la modialisation (Aspects de Droit international privé)”, en Calvo Caravaca, A. e Iriarte, Ángel, J. (eds.), Mundialización y familia, Madrid, Colex, 2001, pp. 11-22; Guzmán Zapater, Mónica y Esplugues Mota, Carlos (dirs.), Persona y familia en el nuevo modelo español de derecho internacional privado, Valencia, Tirant lo Blanch, 2017; González Vicente, P., "Cuestiones internacionales en derecho de familia”, Homenaje a Luis Zarraluqui Sánchez-Eznarriaga. La voz del derecho de familia, Madrid, AEAFA, 2017, pp. 109-117.

4 Hacker, D., Legalized Families in the Era of Bordered Globalization, Cambridge University Press, 2017, pp. passim. Un libro de referencia imprescindible cuando visualizamos una clasificación absolutamente abierta de la familia en un mundo globalizado como el actual y basado en un estudio multidisciplinar. Lowe, N. y Douglas, G., Families across Frontiers, La Haya, Martinus Nijhoff, L, 1996. 
Posteriormente, destacamos el fenómeno más actual en torno a la minoridad, siempre vulnerable, y en esta ocasión referida a los denominados bebés anclas, así como a menores separados de sus familias (III), finalizando con unas no tan breves reflexiones y/o conclusiones, en donde incluimos un repaso somerísimo por todas las medidas que se han ido pergeñando en los últimos meses en el contexto migratorio México-Estados Unidos y en donde el covid-19 no pasa desapercibido (IV).

\section{BIRTHRIGHT CITIZENSHIP \\ EN LOS ESTADOS UNIDOS: IUS SOLI}

En la actualidad, 94 países — aproximadamente la mitad de los Estados reconocidos internacionalmente- consideran la adquisición de la nacionalidad mediante el ius soli; es decir, por el hecho de haber nacido en territorio nacional. ${ }^{6}$ De ellos, 34 países la otorgan sin condiciones (28 en el continente americano y seis en el resto del mundo), ${ }^{7}$ pero cabe señalar que la tendencia actual es hacia la imposición de condiciones para adquirir la nacionalidad mediante ius soli. Un ejemplo de esta tendencia, plasmada en iniciativas de leyes, la encontramos en la política más reciente norteamericana, como veremos más adelante.

En el sistema estadounidense se distingue entre nacionalidad y ciudadanía, si bien tanto los nacionales por nacimiento como los naturalizados tienen la ciudadanía estadounidense. Así, se prevé, en el propio texto de la Decimocuarta Enmienda constitucional, artículo 1o., que se considera nacionales y

5 Véase González Martín, Nuria, "Derecho de nacionalidad en los Estados Unidos de América”, en Lara, María Ángeles (coord.), Normativas de nacionalidad en derecho comparado, Granada, Tirant lo Blanch, 2020.

6 Birthright Citizenship Around the World, Law Library of Congress, noviembre de 2018 , disponible en: https: / /www.loc.gov/law/help/birthright-citizenship/global.php.

7 Angola, Antigua y Barbuda, Argentina, Barbados, Belize, Bolivia, Brasil, Canadá, Cuba, Dominica, Ecuador, El Salvador, Estados Unidos de América, Fiji, Grenada, Guatemala, Guyana, Honduras, Jamaica, Lesotho, México, Nicaragua, Pakistán, Panamá, Paraguay, Perú, Saint Kitts and Nevis, Saint Lucia, Saint Vincent y the Grenadines, Sao Tomé e Príncipe, Tanzania, Trinidad y Tobago, Uruguay y Venezuela, disponible en: https: / /www.loc.gov/law/help/birth right-citizenship/global.php. 
ciudadanos a los nacidos y a los naturalizados en Estados Unidos sujetos a su jurisdicción. De conformidad con la § 101(a) (22) de la Ley de Inmigración y Nacionalidad (INA), el término "nacional de los Estados Unidos" significa: a) un ciudadano de los Estados Unidos, o b) una persona que, aunque no es ciudadano de los Estados Unidos, debe lealtad permanente al país.

Esto significa que existe una equiparación entre ciudadanos y nacionales de Estados Unidos, pues los ciudadanos son nacionales, aunque no todos los nacionales son ciudadanos estadounidenses.

Hasta la fecha, en los Estados Unidos la ciudadanía puede obtenerse a través del mencionado ius soli sin restricciones, o a través de los padres, por naturalización, por matrimonio y por servicios o méritos. ${ }^{8}$ Cuando la ciudadanía es atribuida en virtud de los padres, ésta se puede obtener al nacer o después de haber nacido, pero antes de cumplir los 18 años de edad, mientras que la naturalización es el proceso por el cual se otorga la ciudadanía estadounidense a un ciudadano extranjero después de que éste haya cumplido con los requisitos establecidos por el Congreso de los Estados Unidos en la INA. ${ }^{9}$

En este sentido, tenemos que se puede llegar a ser ciudadano estadounidense por nacimiento por dos vías: a) por haber nacido en territorio estadounidense o en ciertos territorios y posesiones periféricas, estando sujeto a la jurisdicción estadounidense, o b) por tener progenitor o progenitores ciudadanos estadounidenses en el momento del nacimiento del interesado ocurrido fuera de Estados Unidos, cumpliendo ciertos requisitos.

\section{Por haber nacido en territorio estadounidense: ius soli}

La nacionalidad estadounidense por nacimiento está regulada en el título 8o. del USC, subcapítulo III, parte I, en la § 1401(a), relativa a los nacionales y ciudadanos de Estados Unidos por nacimiento: 8 USC 1401 Nationals and Citizens of United States at Birth, o lo que es lo mismo, en la § 301(a) INA. Esta sección dispone que serán nacionales y ciudadanos de Estados Unidos las personas nacidas en Estados Unidos y sujetas a su jurisdicción. Esta regla, basada en el ius soli, es compatible, como mencionamos, con el artículo

8 Disponible en: http://uscode.house.gov/view.xhtml?req=granuleid:USC-prelim-title8-section 1401 \&um $=0$ \&edition $=$ prelim .

9 Immigration and Nationality Act, promulgada el 27 de junio 1952, una norma que contiene importantes disposiciones que regulan la inmigración y la ciudadanía. 
1o. de la Decimocuarta Enmienda a la Constitución de los Estados Unidos, que establece que todas las personas nacidas o naturalizadas en los Estados Unidos y sujetas a su jurisdicción son ciudadanos de los Estados Unidos y del Estado en que residan.

El nacimiento en Estados Unidos incluye también los territorios de la Commonwealth de Puerto Rico, los territorios de Guam, las islas Vírgenes estadounidenses y, después del 4 de noviembre de 1986, la Commonwealth de las islas Mariana del Norte.

El nacimiento en Estados Unidos conlleva la atribución automática de la ciudadanía estadounidense por ius soli conforme a la § 301(a) INA, salvo en caso de hijos de diplomáticos extranjeros, porque no están sujetos a la jurisdicción de Estados Unidos, si bien la exclusión no está totalmente clara. ${ }^{10}$

No se requiere que los progenitores del menor tengan residencia legal en Estados Unidos, por lo que cabe asumir que los menores nacidos dentro de las fronteras estadounidenses y de progenitores extranjeros que se encuentran ilegalmente en el territorio, también adquieren por esta vía la ciudadanía estadounidense.

Igualmente, la 8 USC 1401(b) [§ 301(b) INA] prevé una regla especial basada en el ius soli para los indios nativos americanos, que venían teniendo un estatus especial porque no se consideraban ciudadanos, aunque abandonaran su tribu y se establecieran en territorio americano; sin embargo, a partir de 1924 se les garantizó también la ciudadanía estadounidense a través de la Indian Citizenship Act. ${ }^{11}$ De este modo, también se considerará nacional y ciudadano de Estados Unidos una persona nacida en Estados Unidos y miembro de una tribu india, esquimal, aleutiana o de otra tribu aborigen, siempre que se garantice que esta ciudadanía no afecta de ninguna manera el derecho de dicha persona a la propiedad tribal o a otra propiedad.

El condicionamiento de la transmisión de la nacionalidad estadounidense sobre estas bases se fundamenta en la convicción de que los nativos americanos debían lealtad directa a sus tribus, por lo que sólo debían adquirir la nacionalidad estadounidense si con ello no se veía afectada esta lealtad, quedando abierta la vía para su naturalización. El Congreso extendió la

10 Spiro, P. J., Report on Citizenship Law: United States of America, EUDO Citizenship Observatory, julio de 2015, p. 10, disponible en: https: / / cadmus.eui.eu / bitstream / handle/1814/36498 / EUDO_CIT_CR_2015_13_USA.pdf? sequence $=1$ \&isAllowe $=y$.

11 Disponible en: http://harvardlawreview.org/wp-content/uploads/2017/04/1680-1703_ Online.pdf. 
ciudanía a todos los nacidos en territorio estadounidense, salvo los nacidos en Samoa y las islas Swains, a quienes se les atribuye la nacionalidad estadounidense, pero no la ciudadanía.

Equivalente al nacimiento en Estados Unidos puede considerarse la situación de la persona de parentesco desconocido que se encuentre en el país mientras es menor de cinco años, que se considerará también ciudadana estadounidense por nacimiento hasta que se demuestre, antes de cumplir los 21 años de edad, que no ha nacido en los Estados Unidos, según dispone la 8 USC 1401 (f).

Por ius sanguinis: menores nacidos en el extranjero

Se atribuye la nacionalidad de manera automática. Así, un hijo (o hija) es ciudadano estadounidense si se han reunido las siguientes condiciones reguladas bajo la sección 320 de la INA, según ha sido enmendada por la ley de ciudadanía de hijos (Child Citizenship Act, CCA, por sus siglas en inglés): ${ }^{12}$

- Si por lo menos uno de los padres es ciudadano estadounidense, sea por nacimiento o por naturalización.

- Si el hijo (o hija) es menor de 18 años de edad.

- Si el hijo (o hija) reside en Estados Unidos bajo la custodia legal y física del progenitor ciudadano estadounidense y tiene su residencia permanente legal.

- El hijo (o hija) adoptivo(a) puede obtener la ciudadanía automáticamente si satisface los requisitos bajo las secciones 101(b)(1)(e), (f) o (g) de la INA.

Para ser elegible como "hijo" (o hija) para los propósitos de la sección 320 de la INA, el considerado "hijo" debe ser soltero. Además, si la persona nació sin que sus padres estuvieran casados, debe ser reconocido antes de cumplir 16 años y estar bajo la custodia legal del padre (o la madre) que lo va a reconocer (el padre o la madre que es ciudadano estadounidense). ${ }^{13}$ Por último, un hijastro que no ha sido adoptado no es elegible como hijo bajo esta sección.

12 Disponible en: https://travel.state.gov/content/travel/en/legal/travel-legal-considerations / us-citizenship/Child-Citizenship-2000-Sections-320-322-INA.html.

13 Consulte la sección 101(c)(1) de la INA. 
Una persona que como "hijo" satisface los requisitos de la sección 320 de la INA, antes de cumplir los 18 años es ciudadano automáticamente, sin tener que presentar una solicitud. Sin embargo, si desea obtener un certificado de ciudadanía de los Citizenship and Immigration Services (USCIS, por sus siglas en inglés), debe tramitar el Formulario N-600, Solicitud de Certificado de Ciudadanía. Los pasaportes estadounidenses se hacen a través del Departamento de Estado.

Las personas que hayan cumplido 18 años a la fecha del 27 de febrero de 2001 no son elegibles para obtener la ciudadanía bajo la sección 320 de la INA, según lo ha enmendado la CCA. Estas personas pueden, no obstante, obtener la ciudadanía al amparo de la ley que estaba en vigencia con anterioridad a la enmienda CCA, un tema por demás complicado.

\section{Por naturalización}

La ciudadanía por naturalización se obtiene una vez se cumple con los requisitos que establece la INA, entre los que podemos enunciar los siguientes:

- Antes de la presentación de la solicitud de naturalización, se compruebe una residencia permanente dentro del territorio de los Estados Unidos, de por lo menos cinco años.

- Residido continuamente en los Estados Unidos desde la fecha de la solicitud hasta el momento de la admisión a la ciudadanía.

- Ser una persona respetuosa de los principios de la Constitución estadounidense.

\section{Por matrimonio}

La ciudadanía también puede obtenerse a través del matrimonio. La sección 319 de la INA establece los requisitos para acceder a ésta a través del matrimonio.

La INA establece que cualquier persona cuyo cónyuge sea ciudadano de los Estados Unidos, o cualquier persona que haya obtenido el estatus de residente permanente legal por su condición de cónyuge o hijo de un ciudadano de los Estados Unidos, puede ser naturalizado al cumplir con todos los re- 
quisitos que esa misma ley establece. Algunos de los requisitos que podemos enumerar son los siguientes:

- Si dicha persona, inmediatamente anterior a la fecha de presentar su solicitud de naturalización, ha residido de manera continua durante, al menos, tres años después de haber sido legalmente admitido para residencia permanente dentro de los Estados Unidos, y durante los tres años ha vivido en unión matrimonial con el cónyuge ciudadano.

- Cualquier persona cuyo cónyuge sea ciudadano de los Estados Unidos, o empleado del gobierno o de una institución de investigación estadounidense reconocida como tal por el fiscal general, o de una empresa o corporación dedicada en su totalidad o en parte al desarrollo del comercio exterior de los Estados Unidos, entre otros.

- Cualquier persona que esté empleada por una organización no lucrativa incorporada de buena fe en los Estados Unidos, que se dedique principalmente a realizar en el extranjero, a través de los medios de comunicación, la difusión de información que promueva significativamente los intereses estadounidenses en el extranjero, y que sea reconocida como tal por el fiscal general.

- Cualquier persona que sea el cónyuge, hijo, padre o madre sobreviviente de un ciudadano de los Estados Unidos, cuyo cónyuge, padre o hijo fallezca durante un periodo de servicio honorable en estado de servicio activo en las Fuerzas Armadas, y quien, en el caso de un cónyuge sobreviviente, vivía en unión matrimonial con el cónyuge ciudadano al momento de su muerte.

\section{Por servicios o méritos en las Fuerzas Armadas}

En el sistema norteamericano también se otorga la ciudadanía por servir o haber servido en las Fuerzas Armadas, siempre y cuando se cumplan los requisitos que establece la INA en sus secciones 328 y 329. Los requisitos establecidos en la ley se pueden resumir de la siguiente manera:

- Haber servido honorablemente en las Fuerzas Armadas de Estados Unidos durante tiempo de paz, por un periodo, o periodos, que sumen un año. 
- Haber presentado el formulario necesario, certificación de servicio militar o naval, al momento que se presentó el Formulario N-400 para demostrar el servicio honorable.

- Ser un residente permanente al momento de ser examinado para la solicitud de naturalización.

- Cumplir con ciertos requisitos de residencia y presencia física.

- Demostrar que puede leer, hablar y escribir en inglés.

- Demostrar conocimiento de la historia y el gobierno estadounidense.

- Demostrar que ha sido una persona de buen carácter moral durante, al menos, cinco años antes de presentar el Formulario N-400 y hasta que se naturalice.

- Adherirse a los principios de la Constitución de los Estados Unidos.

En ese mismo orden de ideas, es de señalar que los familiares de miembros de las Fuerzas Armadas estadounidenses pueden optar por asumir la ciudadanía incluso si se encuentran en el extranjero.

Como vemos, y como corolario, hay una variedad de distintos supuestos en los que se contempla la adquisición de la nacionalidad norteamericana por derecho de sangre y otra adquisición, la cual es la protagónica en esta contribución por haber nacido en territorio norteamericano. En definitiva, y ciñéndonos a la nacionalidad por derecho de nacimiento, la mencionada Decimocuarta Enmienda constitucional de los Estados Unidos atribuye la nacionalidad por el ius soli, por el derecho del suelo, por nacer en suelo norteamericano, sin restricciones, y así se establece al enunciar: “Todas las personas nacidas o naturalizadas en los Estados Unidos, y sujetas a la jurisdicción correspondiente, son ciudadanos de los Estados Unidos". ${ }^{14}$ Como

14 U. S. Const. amend. XIV, § 1. ElTribunal Supremo norteamericano ha sido claro en este tema. En 1898 sostuvo, en Estados Unidos vs.Wong Kim Ark (169 U. S. 649,1898), que un niño nacido en los Estados Unidos de ciudadanos chinos, a quienes se les prohibió convertirse en ciudadanos de los Estados Unidos, tenía derecho a la ciudadanía en virtud de la Decimocuarta Enmienda; en 1982 en Plyler vs. Doe (457 U.S. 202 -1982-) la Suprema Corte expresó que la Cláusula de igual protección se aplica a los inmigrantes indocumentados dentro de la jurisdicción de un Estado, no menos que a los inmigrantes documentados y ciudadanos de los Estados Unidos porque están "sujetos a la jurisdicción” de los Estados Unidos. Un antecedente más remoto se da en 1884, con el caso Elk vs.Wilkins, el cual motivó leyes del mismo calado para los americanos nativos, y de ahí la Indian Citizenship Act de 1924. Harrington, Ben, "The Citizenship Clause and «Birthright Citizenship»: A Brief Legal Overview”, Congressional Research Service, 1o. de noviembre de 2018. 
Esta revista forma parte del acervo de la Biblioteca Jurídica Virtual del Instituto de Investigaciones Jurídicas de la UNAM

ya expresamos, se habla de ciudadanía y no de nacionalidad, tomándolo, en apariencia, como sinónimos, algo que para los países del Civil Law se disiente absolutamente. La nacionalidad se otorga —o se debería otorgar por ius soli o por ius sanguinis - ${ }^{15}$ en el momento del nacimiento; la ciudadanía se da cuando se cumple la mayoría de edad, abriendo la posibilidad de adquirir una serie de derechos, como el derecho al voto, que es el más representativo.

En los Estados Unidos, tal y como se deriva de la multimencionada Decimocuarta Enmienda, se estableció — o, más precisamente, hizo explícito para la ciudadanía nacional lo que había sido el caso desde la fundación de la República - la regla de ius soli o ciudadanía basada en el lugar de nacimiento, que es una regla derivada del Common Law inglés. ${ }^{16}$ Los Estados Unidos, como acabamos de exponer, también tienen una tradición de ius sanguinis, ya que otorgan la ciudadanía a los niños nacidos de ciudadanos estadounidenses en el extranjero - siempre que tengan residencia previa en los Estados Unidos- - pero esto es un corolario legal del principio constitucional que asigna la ciudadanía al nacer por territorio.

Los niños nacidos en los Estados Unidos son ciudadanos en virtud de la citada enmienda, pero el estatus de ciudadanía de los niños nacidos de estadounidenses que viven fuera del país se ve afectado por un conjunto com-

15 El enfoque en ius soli, como elemento descriptivo, evita el hecho de que ambas reglas básicas de asignación de la ciudadanía al nacer son adscriptivas, ya sea por geografía o por descendencia (ius sanguinis, después de todo, significa la regla de la sangre). Ninguna persona tiene control sobre las circunstancias de su nacimiento. En este momento no nos detenemos en la adquisición de la nacionalidad del hijo(a) adoptado(a) internacionalmente.

16 Véase el Calvin's Case, (1608) 77 Eng. Rep-377 (K. B.), en Price, Polly J., "Natural Law and Birthright Citizenship in Calvin's Case (1608)", 9 Yale J. L. \& Human, 73, 95 (1997), cit. por Ngai, Mae M., "Birthright Citizenship and the Alien Citizen”, Fordham Law Review, núm. 5, abril de 2007, p. 2525. En este asunto se argumentó que una persona nacida en Escocia después de que James I ascendiera al trono de Inglaterra era un "sujeto nacido natural" y, como tal, tenía derecho a heredar tierras en Inglaterra. El fallo sostuvo que la soberanía del rey que residía en este "corporeal body" era parte de la "ley divina de la naturaleza" y, por lo tanto, más grande que las jurisdicciones políticas bajo su soberanía. En la Inglaterra del siglo XVII la temática era principalmente una cuestión de lealtad, ya que los beneficios de los sujetos nacidos de forma natural eran escasos, pero éstos incluían el derecho a heredar tierras y demandar en las cortes del rey. De acuerdo con el Caso Calvino de 1608, y refiriéndonos a las colonias norteamericanas, el Common Law de Inglaterra, en principio, es aplicable; los súbditos de la Corona británica lo llevan consigo cuando se establecen en territorios no sometidos a naciones civilizadas. 
plejo de leyes. Cuando los padres de esos niños no están casados, esas leyes dificultan la transmisión de la ciudadanía entre el padre y su hijo, al tiempo que proporcionan una transmisión casi automática de la ciudadanía entre una madre estadounidense y su hijo. ${ }^{17}$ Hay tres casos que implicaron un gran desafío constitucional a la regulación basada en el género de la transmisión de la ciudadanía entre padres e hijos (Miller vs. Albright, Nguyen vs. INS y Flores-Villar vs. Estados Unidos), y la Suprema Corte confirmó estas distinciones mientras trabajaba para explicar por qué el Congreso ha elaborado líneas tan marcadas entre los hijos no matrimoniales de madres y padres estadounidenses. $^{18}$

Para finalizar, es importante subrayar que los opositores a la ciudadanía por nacimiento, en general, no discuten directamente en términos de exclusión racial. Esto puede deberse a que no están motivados por el ra-

17 Para asegurar la ciudadanía de su hijo no marital nacido en el extranjero el 14 de noviembre de 1968, o después de esa fecha, el padre debe proporcionar una prueba de paternidad o legitimación antes de que el niño cumpla los 18 años y una prueba de provisión de apoyo financiero. Además, una relación de sangre entre el niño y el padre debe establecerse mediante "pruebas claras y convincentes" y el padre debe cumplir con un requisito de residencia calibrado por edad. Ver 8 U. S. C. 1401 (g), 1409 (a). Por el contrario, la madre de un niño no marital nacido en el extranjero sólo debe haber vivido en los Estados Unidos durante un año en cualquier momento de su vida. Ver id. 1409 (c). Los requisitos para la transmisión de la ciudadanía padre-hijo fuera del matrimonio han variado desde que se codificaron por primera vez en 1940, mientras que los estándares liberales para la ciudadanía madre-hijo se ha mantenido esencialmente igual. Comparar la Ley de Nacionalidad de 1940, cap. 876, 201-205, 54 Stat. 1137, 1138-40, con 8 U. S. C. 1409 (c). Debido a que el Congreso generalmente no ha realizado cambios retroactivos a los requisitos que se aplican a los hijos no matrimoniales de los padres estadounidenses, los estándares más antiguos siguen siendo las leyes vigentes para los niños que alcanzan la mayoría de edad antes de la fecha efectiva de un cambio posterior. Véase Collins, Kristin A., "Illegitimate Borders: ius sanguinis Citizenship and the Legal Construction of Family, Race, and Nation", The Yale Law Journal, vol. 123, núm. 7, mayo de 2014, pp. 2136 y 2137.

18 Véase Flores-Villar v. Estados Unidos, 131 S. Ct. 2312 (2011) (per curiam) por una corte igualmente dividida 536 F. 3, 990 (9 Cir. 2008); Nguyen v. INS, 533 U. S. 53, $56-57$ (2001); Miller v. Albright, 523 U. S. 420, 424 (1998). Nguyen y Miller, con desafíos para el padre al establecer sólo requisitos de legitimación y prueba de paternidad de 8 U: S. C. 1409 (a) y 8 U. S. C. 1409 (a) (b), mientras que Flores-Villar desafió los requisitos dispares de residencia de los padres que se aplican a los padres y madres de niños no nacidos en el extranjero. Comparar 8 U. S. C. 1409 (a) (7) (1970) con id. 1409 (c). Si bien el Congreso redujo la duración del requisito de residencia de los padres en forma retrospectiva en 1986, la ley continúa manteniendo a las madres y los padres de niños nacidos en el extranjero no maritales a diferentes estándares. Comparar 8 U. S. C. 1401 (a) (2012) con id. 1409 (c). 
cismo, o si lo están, saben que es socialmente inaceptable y legalmente dudoso. La exclusión racial de la ciudadanía tiene una larga historia en los Estados Unidos, una que ha involucrado diferentes manipulaciones de la ciudadanía territorial y de ascendencia. Incluso si la exclusión racial no es el resultado pretendido de eliminar la ciudadanía por nacimiento, produce un cierto resultado. ${ }^{19}$

\section{MINORIDAD EN ESTADO DE VULNERABILIDAD}

\section{Categorización de inicio}

Junto con las categorías esbozadas de familias y con las distintas "modalidades", encontramos menores "dejados atrás" no sólo físicamente, sino simbólicamente; desde que quedan atrás, dejando su voz, sus derechos más elementales, y en donde la vulnerabilidad se torna en un estado - estado de vulnerabilidad - que cambia, y no necesariamente de manera positiva..$^{20}$ Categorizamos, además, a aquellos niños, niñas y adolescentes víctimas de trata y explotación laboral, sexual, o con fines de tráfico de órganos, entre otros. Asimismo, incluimos la minoridad que se traslada sola, o bien, para reagruparse con su núcleo familiar; para poder enviar remesas, fruto de su trabajo en otro país, o para, simple y llanamente, salir de una situación intolerable en sus países de origen. Sin olvidar a los menores que son separados de sus familias por políticas migratorias que vulneran su derecho a vivir con sus familias.

Sin lugar a dudas, hay un falso universalismo de los derechos humanos en los Estados y una absoluta ignorancia de la protección de niñas, niños y adolescentes - el denominado adultocentrismo- - en donde si con respecto a los adultos existe un alto grado de desigualdad, el tema se recrudece cuando hablamos de menores, y más aún de menores migrantes.

19 Ngai, Mae M., "Birthright Citizenship and the Alien...", cit. p. 2527.

20 Como lo señala Bustamante, el estado de vulnerabilidad surge en el extranjero cuando hay una "diferencia o ausencia de poder, que los coloca en una posición de subordinación en sus relaciones sociales con los nacionales, ya sean éstos individuos o instituciones”. Bustamante, Jorge, Migración internacional y derechos humanos, México, UNAM, 2002, p. 176. 
La protección de derechos humanos, en general (ciudadanía y nacionalidad), y el sistema de protección de los menores, en particular (familia, sociedad y Estado)' están en proceso de cambio; cambio de estrategias: flujos migratorios que llegan con la intención de quedarse y no de residir temporalmente.

La Convención de Naciones Unidas sobre los Derechos del Niño de 1989 (CNU'89), la carta magna de la niñez, ha servido para desmantelar la consideración de la niñez migrante acompañada como la única existente y para construir una nueva categorización en la que tiene cabida la niñez inmigrante no acompañada en sus múltiples perfiles y tipologías. ${ }^{21}$ De esta manera, se debe diferenciar entre "menor extranjero —o migrante — no acompañado" y “menor extranjero separado".

El menor migrante no acompañado(a) se encuentra solo, sin la compañía de ningún familiar, guardián o tutor legal (artículo 20 CNU'8922). Los menores migrantes no acompañados, o los menores extranjeros no acompañados (MENA's, como se les conoce en el contexto europeo), están definidos en ese artículo 20 como "niño privado de su entorno o medio familiar", concebidos con el más alto nivel de vulnerabilidad al estar solos y alejados de su familia y de sus referentes culturales. Se hace notar que el Comité de los Derechos del Niño, en su Observación General Núm. 6, se refiere a los menores extranjeros no acompañados.

Otra categorización la tenemos con el menor extranjero separado de sus progenitores o de sus tutores (b), pero no de otros familiares (artículos 90.

21 El Comité de los Derechos del Niño, como órgano de interpretación, supervisión y control de la Convención de Naciones Unidas de 1989 (artículos 43 a 45 CNU'89), es un órgano que emite observaciones generales que sirven de guía de actuación a los Estados parte; órgano que identifica al colectivo de menores y que tiene un papel toral.

22 Artículo 20. “1. Los niños temporal o permanentemente privados de su medio familiar, o cuyo superior interés exija que no permanezcan en ese medio tendrán derecho a la protección y asistencia especiales del Estado. 2. Los Estados Partes garantizarán, de conformidad con sus leyes nacionales, otros tipos de cuidado para esos niños. 3. Entre esos cuidados figurarán, entre otras cosas, la colocación en hogares de guarda, la kafala del derecho islámico, la adopción, o de ser necesario la colocación en instituciones adecuadas de protección de menores. Al considerar las soluciones, se prestará particular atención a la conveniencia de que haya continuidad en la educación del niño y a su origen étnico, religioso, cultural y lingüístico". Disponible en: https: / /www.un.org/es/ (fecha de consulta: 20 de marzo de 2020). 
Esta revista forma parte del acervo de la Biblioteca Jurídica Virtual del Instituto de Investigaciones Jurídicas de la UNAM

y 10 CNU' 89), ${ }^{23}$ situación de los separados y la reunificación familiar en el Estado del que no son nacionales.

Con referencia a los menores migrantes no acompañados, por su situación de doble o triple factor de vulnerabilidad son sujetos directos de protección, en donde el fin primordial debe ser el de reducir las barreras que impiden u obstaculizan el ejercicio de sus derechos. En definitiva, el establecimiento de normas que imponen obligaciones al Estado para aquellos supuestos en los que menores y adolescentes estén en situación de vulnerabilidad y

23 Artículo 9.1. "Los Estados Partes velarán porque el niño no sea separado de sus padres contra la voluntad de éstos, excepto cuando, a reserva de revisión judicial, las autoridades competentes determinen, de conformidad con la ley y los procedimientos aplicables, que tal separación es necesaria en el interés superior del niño. Tal determinación puede ser necesaria en casos particulares, por ejemplo, en los casos en que el niño sea objeto de maltrato o descuido por parte de sus padres o cuando éstos viven separados y debe adoptarse una decisión acerca del lugar de residencia del niño. 2. En cualquier procedimiento entablado de conformidad con el párrafo 1 del presente artículo, se ofrecerá a todas las partes interesadas la oportunidad de participar en él y de dar a conocer sus opiniones. 3. Los Estados Partes respetarán el derecho del niño que esté separado de uno o de ambos padres a mantener relaciones personales y contacto directo con ambos padres de modo regular, salvo si ello es contrario al interés superior del niño. 4. Cuando esa separación sea resultado de una medida adoptada por un Estado Parte, como la detención, el encarcelamiento, el exilio, la deportación o la muerte (incluido el fallecimiento debido a cualquier causa mientras la persona esté bajo la custodia del Estado) de uno de los padres del niño, o de ambos, o del niño, al Estado Parte proporcionará cuando se le pida, a los padres, al niño o, si procede, a otro familiar información básica acerca del paradero del familiar o familiares ausentes, a no ser que ello resultase perjudicial para el bienestar dl niño. Los Estados Partes se cerciorarán, además, de que la presentación de tal petición no entrañe por sí misma consecuencias desfavorables para la persona o personas interesadas”.

Artículo 10.1. "De conformidad con la obligación que incumbe a los Estados Partes a tenor de lo dispuesto en el párrafo 1 del artículo 9o., toda solicitud hecha por un niño o por sus padres que entrar en un Estado Parte o para salir de él a los efectos de la reunión de la familia será atendida por los Estados Partes de manera positiva, humanitaria y expeditiva. Los Estados Partes garantizarán, además, que la presentación de tal petición no traerá consecuencias desfavorables para los peticionarios ni para sus familiares. 2. El niño cuyos padres residan en Estados diferentes tendrán derecho a mantener periódicamente, salvo en circunstancias excepcionales, relaciones personales y contactos directos con ambos padres. Con tal fin, y de conformidad con la obligación asumida por los Estados Pares en virtud del párrafo 1 del artículo 9o., los Estados Partes respetarán el derecho del niño y de sus padres a salir de cualquier país, incluido el propio, y de entrar en su propio país. El derecho a salir de cualquier país estará sujeto solamente a las restricciones estipuladas por la ley y que sean necesarias para proteger la seguridad nacional ,el orden público, saludo o la moral pública o los derechos y libertades de otras personas que estén en consonancia con los demás derechos reconocidos por la presente Convención”. Disponible en: https://www.un.org/es/ (fecha de consulta: 20 de marzo de 2020). 
se reduzcan las mayores barreras que encuentren para el ejercicio de sus derechos. Los menores migrantes no acompañados, por tanto, son vulnerables:

1) Por su consideración de ser o estar privados de su ambiente familiar; es decir, estar solo o no acompañado por la familia.

2) Por su condición de niño, donde son discriminados de manera múltiple:

- Refugiados (artículo 22 CNU'89)

- Discapacitados (artículo 23 CNU'89)

- Estar a cargo de instituciones públicas (artículo 25 CNU'89)

- Pertenecer a grupos minoritarios o indígenas (artículo 30 CNU'89)

- Encontrarse en conflictos armados (artículo 39 CNU'89)

- Estar en conflicto con la ley (artículo 40 CNU'89)

- Víctimas de trata de seres humanos (artículo 35 CNU'89)

- Vivir en la calle, víctimas de violencia de género, trabajadores irregulares y siempre más expuestos al trabajo infantil, explotación laboral (artículo 32 CNU'89), consumo de drogas (artículo 33 CNU'89), explotación sexual (artículo 34 CNU'89), secuestro, venta y trata (artículo 35 CNU'89) u otras formas de explotación (artículo 36 CNU'89) y detención y castigo (artículo 37 CNU'89).

El Comité de los Derechos del Niño, a través de la mencionada Observación General Núm. 6, ha intentado clarificar quiénes forman parte del grupo social de menores no acompañados, atendiendo al mencionado artículo 20 CNU' 89 y a la realidad migratoria actual. De su lectura deducimos cinco tipologías de menores y adolescentes migrantes no acompañados: 1) niños solicitantes de asilo; 2) niños refugiados; 3 ) niños víctimas de trata; 4) niños impedidos, y 5) niños soldados.

Asimismo, de la Observación General Núm. 21, se agrega la de niños en situación de calle. Sin embargo, quedaría sin contemplarse una última categoría relacionada: la niñez inmigrante económica no acompañada, ${ }^{24} \sin$ mencionar a aquellos que huyen al ser rechazados por sus familias, ya sea por cuestiones de sexualidad (identificados como lesbianas, gais, bisexuales, transgénero, in-

24 Véase Serrano Sánchez, Lucia, "Vulneraciones y acceso a los sistemas de protección de los derechos de la niñez y adolescencia migrante no acompañada en España y El Salvador”, tesis doctoral, Programa de Doctorado en Ciencias Jurídicas, Universidad de Granada, España, defensa: 9 de julio de 2019, tesis inédita y premio a mejor tesis doctoral, Universidad Internacional de La Rábida. 
Esta revista forma parte del acervo de la Biblioteca Jurídica Virtual del Instituto de Investigaciones Jurídicas de la UNAM

tersexuales, asexuales), por ser pandilleros o porque son niños que ofrecen resistencia al matrimonio infantil o a la mutilación femenina. ${ }^{25}$

2. Casuística derivada de los Estados Unidos de América

\section{Bebés anclas}

Al inicio de esta contribución hemos hecho hincapié en la tendencia más actual de aquellos países que consagran la nacionalidad por ius soli sin reserva hacia la imposición de restricciones, y así, de esta manera, buscar otras formas de acotar el acceso a nacionalidades, digamos, automáticas.

Cuando hablamos de bebés anclas ${ }^{26}$ (Anchor Baby), nos referimos a aquellos casos en los que se trata de asegurar la nacionalidad en otro país con un movimiento de corto plazo; es decir, esos padres que deciden dar a luz en un determinado país para garantizar la nacionalidad por el simple hecho de nacer en su suelo, ius soli, como es el caso de los Estados Unidos. Un tema que no pasan por alto las autoridades americanas, máxime si subrayamos que al cumplir los 21 años de edad, los hijos pueden solicitar el trámite de residencia permanente para sus progenitores. ${ }^{27}$

A partir de 2005, el término bebé ancla se utilizó ampliamente para describir a los hijos de mujeres pobres de color, concretamente inmigrantes latinas no documentadas, que se suponía daban a luz en los Estados Unidos para obtener ganancias financieras a expensas de los contribuyentes. ${ }^{28}$

25 Idem.

26 Aunque tendría cabida, en esta oportunidad no nos referiremos al turismo por nacimiento o turismo de maternidad por cuestiones de acotación de la materia. Para una referencia al respecto, recomendamos la lectura de algo previo que escribimos en González Martín, Nuria, "Apuntes desde el derecho internacional privado relacionados con los «niños dejados atrás»: especial consideración a los menores no acompañados y familias separadas”, en Pérez Contreras, Montserrat y Macías y Pérez, Elisa (coords.), Derechos humanos, migración y desplazamiento forzado, México, UNAM, Instituto de Investigaciones Jurídicas, 2020.

27 Padre de un ciudadano estadounidense que tiene, al menos, 21 años de edad. Categorías de elegibilidad de Green Card, disponibles en: uscis.gov (fecha de consulta: 20 de marzo de 2020).

28 Tiffany, Joseph, “Anchor Babies and the Challenge of Birthright Citizenship”, Contemporary Sociology, vol. 47, núm. 6, noviembre de 2018, pp. 691 y ss.; Kim, J. K. et al., "Genderacing Immigrant Subjects: «Anchor Babies» and the Politics of Birthright Citizenship”, Social Identities, vol. 24, núm. 3mayo de 2018, pp. 312-326. 
La respuesta legislativa a esta amenaza percibida fue la Birthright Citizenship Act (H. R. 140). ${ }^{29}$ Esta Ley de ciudadanía por derecho de nacimiento negaría la ciudadanía a los niños nacidos en los Estados Unidos a menos que uno de los padres del niño sea ciudadano, residente legal permanente o residente legal que preste servicio militar. Aunque, dicha ley violaría el texto de la Decimocuarta Enmienda constitucional, así como leyes secundarias. ${ }^{30}$

Los Birthright Citizenship Bills; es decir, los proyectos de ley de ciudadanía/nacionalidad por derecho de nacimiento, propuestas para restringir la ciudadanía natural de ius soli para los niños nacidos en Estados Unidos, revelan, insistimos, que el complejo enredo de género, estado de nacimiento y raza también continúa en las batallas políticas sobre inmigración y ciudadanía. Estas propuestas, calculadas para excluir a los hijos de madres no ciudadanas y no documentadas del estado de ciudadanía de personas de ascendencia hispana, negarían la ciudadanía a los niños nacidos en Estados Unidos de madres indocumentadas. Como decimos, si bien estos proyectos de ley son neutrales en cuanto a la raza, el testimonio en el Congreso de quienes proponen tales medidas deja claro que el problema principal, tal como lo formulan, es no reconocer como ciudadanos a los hijos de madres indocumentadas. ${ }^{31}$

29 "To amend section 301 of the Immigration and Nationality Act to clarify those classes of individuals born in the United States who are nationals and citizens of the United States at birth". Disponible en: https://www.congress.gov/bill/116th-congress/house-bill/140/text. Esta iniciativa se introdujo el 3 de enero de 2019 a la Cámara de Representantes y, actualmente, tiene 28 co-sponsors; es decir, el legislador que presenta una bill/act para su consideración. El último se adhirió el 13 de febrero de 2019, donde plantean modificar, como decimos, la sección 301 de la Immigration Act para instaurar tres supuestos en los cuales se podría otorgar la nacionalidad estadounidense: i) que un padre sea de nacionalidad estadounidense; ii) que el padre/madre sea extranjero pero tenga residencia legal en Estados Unidos, o iii) que su padre/madre sea un miembro activo de las Fuerzas Armadas.

30 Como vimos en el primer apartado de esta contribución, la Immigation and Nationality Act (INA) incluso amplía la nacionalidad y ciudadanía por nacimiento en su artículo 301 (a): "una persona nacida en los Estados Unidos, y sujeta a su jurisdicción” es un "nacional y ciudadano de los Estados Unidos al momento de nacer”. La INA también extiende la ciudadanía en el momento del nacimiento a aquellas personas que no están protegidas por la cláusula de ciudadanía, como las nacidas en el extranjero de algunos padres ciudadanos estadounidenses. Las regulaciones federales, incluidas las que rigen la emisión de pasaportes y el acceso a ciertos beneficios, implementan la INA al proporcionar que una persona es un ciudadano estadounidense si él o ella nació en los Estados Unidos, siempre que el padre no fuera un "oficial diplomático extranjero" en el momento del nacimiento.

31 Collins, Kristin A., "Illegitimate Borders...”, cit., p. 2224. 
Esta revista forma parte del acervo de la Biblioteca Jurídica Virtual del Instituto de Investigaciones Jurídicas de la UNAM

Como ya expresamos, la ley de ciudadanía por derecho de nacimiento actualmente se encuentra bajo consideración en el Congreso de los Estados Unidos, ${ }^{32}$ con el objetivo de negar la ciudadanía por derecho de nacimiento. La ley, desde su propio nombre "engañoso", invita a un replanteamiento más que contundente hacia su rechazo. ${ }^{33}$

En este caso concreto, relativo a los bebés anclas, dicha nomenclatura se hace muy visible, al menos a través de la prensa más mediática, desde que el presidente Trump inició su candidatura presidencial en 2015 y acometió contra la ciudadanía por derecho de nacimiento ${ }^{34}$ y la Decimocuarta Enmienda constitucional (Birthright Citizenship); contra los hijos de los inmigrantes no documentados, llamándolos despectivamente bebés anclas y con ello, de manera paralela, acusando a las mujeres migrantes de "undermining of the United States". ${ }^{35}$ Se presenta así, y sin lugar a dudas, el escenario más peyorativo y denigrante que un panorama discriminador puede evocar. ${ }^{36}$

$32116^{\text {th }}$ Congress, $1^{\text {st }}$ session, January 3, 2019.

33 Véase el rechazo rotundo de la declaración de 7 de diciembre de 2018, de la U. S. Commission on Civil Rights, la cual se opone a dicha iniciativa que atenta para acabar con el derecho de ciudadanía por nacimiento y en clara continuidad con la hostilidad contra los inmigrantes, disponible en: www.usccr.gov. Véase, igualmente, Foster, C. H., "Anchor Babies and Welfare Queens: An Essay on Political Rhetoric, Gendered Racism, and Marginalization”, Women, Gender, and Families of Color, Estados Unidos, vol. 5, núm. 1, primavera de 2017, p. 51. Esta ley de ciudadanía por nacimiento en realidad negaría la ciudadanía por derecho de nacimiento y por ello es importante expresar que tan nefasta es que ni siquiera el nombre del proyecto de ley se acerca fidedignamente a su contenido.

34 Como decimos, desde 2015 el presidente Trump ha promovido esta iniciativa. Véase https: / / thehill.com/blogs/pundits-blog/immigration/251768-on-birthright-citizenship-congresscant-trump-constitution). Sin embargo, ha recibido muchas críticas por su falta de fundamento legal y la clara violación a derechos humanos que tal modificación pudiera representar. El rechazo por el congreso ante este tipo de iniciativas se puede consultar en: https: / / www.usccr. gov/press/2018/12-07-Birthright-Citizenship-Statement.pdf.

35 Queremos hacer notar aquí que tanto las denominaciones de "bebé ancla" (anchor Baby) como de "reina del bienestar" (welfare queen) son ejemplos de una "retórica política racista de género utilizada públicamente por los legisladores para marginar a las poblaciones vulnerables. En los años ochenta y noventa, los legisladores utilizaron la frase «reina del bienestar» para describir a las mujeres solteras pobres que tenían varios hijos, supuestamente con el propósito de obtener ganancias financieras a expensas de los contribuyentes de los Estados Unidos. Como decimos, el término «bebé ancla» se ha utilizado más recientemente para describir a los hijos de mujeres inmigrantes no documentadas que, según afirman algunos legisladores, vienen a los Estados Unidos a tener bebés”. Foster, C. H., op. cit., p. 50.

36 Kim, J. K. et al., op. cit., p. 313. 
El tema que subyace, y que debería hacernos pensar, es sobre lo justo o injusto que puede ser cómo determinar quién puede dar a luz a los ciudadanos en los Estados Unidos.

\section{Familias separadas en la frontera México-Estados Unidos ${ }^{37}$}

\section{Una situación real que hace patente la falta de sensibilidad, por decir} lo menos, de la administración Trump, es la situación en donde los niños migrantes eran separados de sus padres o del adulto que los acompaña. ${ }^{38}$

37 González Martín, Nuria, “Globalización familiar...”, cit.

38 Vulnerando uno de los principios rectores establecidos desde la carta magna de la niñez; es decir, la Convención de Naciones Unidas sobre los Derechos del Niño de 1989, ratificada por la comunidad internacional en su totalidad, con la excepción de los Estados Unidos de América, en donde su artículo 9o., inciso I, subraya el derecho del niño a vivir con ambos padres, y el artículo 10, inciso I, se refiere a la reunificación familiar de manera expedita, positiva y humana.

El número de familias detenidas en la frontera ha crecido exponencialmente y los peligros latentes son más que evidentes, y máxime para los menores inmersos en estas situaciones. Véase, en ese sentido, las cifras y las realidades expuestas en Lakosil, N., "The Flores Settlement: Ripping Families Apart under the Law", Golden Gate U. L. REv, vol. 48, 2018 , pp. 31 y ss.

Véase \#kidsarewaiting Facebook Live Chat, realizado en vivo el 29 de agosto de 2018 a las 13:00 h (hora del Este). En donde el International Social Service-USA maneja una serie de cifras que no dejan indiferente a nadie: "2,000 migrant \#kidsarewaiting to be reunited with their families across the U. S. Mexico border; 20,000 \#kidsarewaiting to leave group homes in the U. S.; 30,000 \#kidsarewaiting to be deinstituionalized in the U. S.; 107,000 \#kidsarewaiting to be adopted in the U. S.; 100,000 \#kidsarewaiting in U. S. Foster care for their families in foreign countries to be engaged in permanency planning for them; 193,000 \#kidsarewaiting in non-relaive Foster homes to be reunited with family".

Creemos conveniente expresar que la situación no es exclusiva de un solo país, y dado que el tema lo hemos vinculado México-Estados Unidos, debemos expresar que México, igualmente, es un país de origen, tránsito, destino y retorno de migrantes con grandes retos sobre la materia, y no sólo teórico, sino en la práctica diaria. Véase Fernández de la Reguera, Alethia et al., "Caravanas migrantes: las respuestas de México”, México, UNAM, Instituto de Investigaciones Jurídicas, 2019, Opiniones Técnica sobre Temas de Relevancia Nacional, núm. 8, disponible en: https://biblio.juridicas.unam. $\mathrm{mx} / \mathrm{bjv} /$ detalle-libro/5804caravanas-migrantes-las-respuestas-de-mexico-serie-opiniones-tecnicas-sobre-temas-de-relevancianacional-num-8. 
Esta revista forma parte del acervo de la Biblioteca Jurídica Virtual del Instituto de Investigaciones Jurídicas de la UNAM

En este contexto, iniciado en abril de 2018, pareciera que se podría hablar de una "nueva" categoría de menores desprotegidos a los que se les infringe un daño irreparable. ${ }^{39}$ Un ejemplo de ello la tenemos bajo la denominada doctrina de "tolerancia cero" en los Estados Unidos, ${ }^{40}$ por la que todo inmigrante indocumentado se considera un delincuente y se le procesa judicialmente como tal, aunque no tenga antecedentes penales, y por tal "motivo" los niños no pueden seguir junto a sus padres y son separados. ${ }^{41}$ Un resultado frecuente en estos casos es la deportación de los padres ${ }^{42} \mathrm{y}$, por tanto, los niños son entregados a un cuidador, o sponsor, o son colocados

39 La realidad es que creció el número de afectados por la deportación de progenitores, pero también de cónyuges. "Como resultado del reciente aumento en las deportaciones de personas con vínculos a largo plazo con los Estados Unidos, cientos de miles de los matrimonios de ciudadanos estadounidenses han sido socavados fundamentalmente. Algunos permanecen en los Estados Unidos sin sus parejas de por vida; otros abandonan el país para mantener juntas a sus familias. De cualquier forma, experimentan dificultades financieras, psicológicas y emocionales. Quienes deciden irse son desarraigados, pierden la proximidad con sus familiares y amigos, el acceso a sus propiedades y las oportunidades profesionales para las que se capacitaron en los Estados Unidos. Se enfrentan a barreras culturales y de idioma una vez que se mudan al extranjero" (la traducción es nuestra). Caldwell, B., "Deported by Marriage. Americans Forced to Choose between Love and Country”, Brook Law Review, vol. 82, 2016, pp. 1 y ss.

40 La Fiscalía anunció, en abril de 2018, una estrategia de "tolerancia cero" que implicaba presentar cargos penales contra cualquier adulto que entrara ilegalmente a los Estados Unidos. Si viajaban con niños, como los menores no pueden ser encarcelados, eran segregados de sus padres. Se les trasladaba a un albergue de Servicios Sociales donde permanecían hasta que se encontrara una familia de acogida.

${ }^{41}$ La crisis estalló en la opinión pública cuando se hizo público que en el lapso de seis semanas, entre el 19 de abril y el 6 de junio de 2018, la Administración había separado a unos 2,000 niños, a veces bebés, de sus progenitores o familiares adultos. Trump suspendió, a través de una orden ejecutiva, el 20 de junio de 2018, su política de separación de familias en la frontera. No obstante, en paralelo se siguió obligando a los menores a declarar ante un juez, vulnerando derechos de los menores a mansalva. Disponible en: www.elpais.es, 7 de julio de 2018.

42 Los padres inmigrantes detenidos por funcionarios de inmigración corren el riesgo de perder sus derechos parentales mucho más rápidamente que los padres nacidos en Estados Unidos que están encarcelados. La deportación no debe considerarse motivo suficiente para la terminación del derecho parental. Incluso como resultado, los niños con recursos familiares en otro país a menudo son injustamente liberados/propuestos para su adopción, y corren el riesgo de perder la conexión con su familia, su cultura, su idioma, y otras fuentes importantes de desarrollo saludable. ISS, Developing Sustainable Repatriation and Reintegration Programs for Children and Families Separated by Borders, julio de 2018, p. 2. 
en hogares de acogida federales, ${ }^{43}$ con medidas de seguimiento "adecuadas" para garantizar la seguridad y el bienestar de los niños. ${ }^{44}$

Según los últimos datos de 2018, el gobierno de los Estados Unidos tenía bajo custodia a 11,351 menores inmigrantes en un centenar de centros. ${ }^{45}$ El presidente justificó esta medida porque implicaba el cumplimiento de la actual ley migratoria y la responsabilidad recaía en los legisladores, invitando a la creación de una nueva normativa. Pero la realidad era otra: la práctica de separar a los menores de sus familiares no responde a ninguna ley, y de ahí la orden ejecutiva del 20 de junio de 2018 que paralizó la medida. La idea fue replantear la práctica de la denominada "tolerancia cero" a través de una nueva legislación migratoria que aborda-

43 Por una cuestión práctica-económica, en promedio, los niños que están en un centro de crianza, los denominados foster care, cuestan al sistema estatal de protección infantil más de $\$ 30,000$ por año. Invertir en la colocación segura de un niño con su familia en otro país puede ahorrar dinero a los sistemas estatales mientras trabaja para mantener unidas a las familias cuando es en el mejor interés del niño. Idem.

Pero por una cuestión menos económica, veamos cómo proteger a nuestros menores aportando el apoyo legal y emocional efectivo. Véase nuestra propuesta general de un mediador intercultural en González Martín, Nuria, "Vulnerable Migrants: Mediation for Unaccompanied Minors in the Border between US/Mexico", Newsletter Weinstein International Foundation, 2020.

44 ISS, Developing Sustainable Repatriation and Reintegration Programs for Children and Families Separated by Borders, julio de 2018, p. 2. De manera similar, la suspensión del Estatus de Protección Temporal (Temporary Protected Status, TPS, por sus siglas en inglés) para ciudadanos salvadoreños, haitianos, hondureños y nicaragüenses, deja a miles de niños y padres vulnerables en la aplicación de la ley de inmigración. Estas familias tendrán dificultades con la decisión sobre qué hacer si son detenidos y/o deportados. ¿Deberían los niños regresar con ellos o deberían quedarse en los Estados Unidos? Estas decisiones son emocionalmente complejas para los miembros de la familia y generan recursos ya de por sí limitados. Disponible en: http://cimmcw.org/wp-content/uploads/ISS-Practice-Brief.pdf (fecha de consulta: 13 de diciembre de 2019).

45 La Cancillería mexicana emitió un comunicado de prensa el 19 de junio de 2018 en torno a la situación. Disponible en: https://www.gob.mx/sre/prensa/condena-el-gobierno-demexico-la-politica-de-separacion-de-familias-migrantes-en-estados-unidos. Claramente, se declara dicha "acción como cruel e inhumana [...] representa una violación a los derechos humanos de los migrantes y pone en situación de vulnerabilidad a niñas y niños [...] Los casos de menores mexicanos que se encuentran en esta situación son pocos, en torno al 1\%, y están identificados con el debido acompañamiento de los consulados de México. El mayor número de menores separados de sus familias corresponde a niñas y niños provenientes de Guatemala, El Salvador y Honduras. Las organizaciones civiles están dando seguimiento al tema de manera muy puntual”. 
Esta revista forma parte del acervo de la Biblioteca Jurídica Virtual del Instituto de Investigaciones Jurídicas de la UNAM

ra el problema; no obstante, el Congreso no llegó a ningún acuerdo sobre la reforma migratoria.

Como vemos, la administración de Trump parecía enfocarse no sólo en la construcción de un "nuevo" muro entre México y los Estados Unidos ${ }^{46}$ sino en la población más vulnerable; primero, poniendo en duda la permanencia de los llamados dreamers (o soñadores) y después culpando a los legisladores por la separación de las familias.

Como decimos, desde abril de $2018^{47}$ la administración Trump comenzó a separar, de forma generalizada, a las familias que intentaban entrar ilegalmente en el país. Las imágenes de hileras de niños en tiendas de campaña y las grabaciones de sus llantos dando la vuelta al mundo fueron el detonante para que la sociedad se percatara de una situación por demás aberrante justo en pleno siglo XXI. Así que California, como estado

46 Las autoridades norteamericanas insisten en construir un muro en la frontera "es más que sólo un muro, es un sistema de muro transfronterizo". "Los expertos (sic. norteamericanos) han concluido que el muro es absolutamente necesario para asegurar la frontera y que si funciona”. Brooks, David, “Baja migración 56\%, pero EU insiste en que México sea declarado tercer país seguro”, La Jornada, 10 de septiembre de 2019, p. 10.

En el mismo tenor, la administración Trump ha enviado cartas a docenas de residentes en California, Nuevo México y Texas, expresando que el gobierno inspeccionará sus tierras para ver el tema del muro fronterizo, se pergeña la idea de que el gobierno puede adquirir tierras privadas para uso público. Disponible en: https: / / www.cnn.com/2019/11/21/politics/eminentdomain-border-wall $/$ index.html?utm_source $=C N N+$ Five + Things\&utm_campaign $=a c 4 a b 0 b c 3 f$ EMAIL_CAMPAIGN_2019_11_22_03_04\&utm_medium=email\&utm_term=0_6da287d761 ac4abObc3f-100712849 (noviembre 22 de 2019).

47 Un relato pormenorizado de lo acontecido lo podemos ver en la decisión United States District Court Southern District of California, Case No. 18 cv0428 DMS (MDD) Order Granting Plaintifss Motion for Classwide Preliminary Injunction, del 26 de junio de 2018, donde se habían ordenado una serie de medidas dirigidas a facilitar la comunicación regular entre los niños y niñas con sus padres y lograr la reunificación en plazos específicos; el último se venció el 26 de julio de 2018. Disponible en: https: / $/$ www.politico.com/f/?id=00000164$3 f 39-d 1 b c-a f e f-7 f b b d f 010001$.

Los documentos judiciales exponen con crudeza cómo el gobierno actuaba sin un plan definido mientras colocaba a niños de escasa edad en una vía legal totalmente separada de la de sus padres. Las autoridades no saben con certeza dónde están algunos adultos — por ejemplo, algunos excarcelados - ni cuántos niños fueron exactamente separados de sus padres. La administración también reconoce la dificultad de contactar a un adulto cuando ya ha sido deportado a su país de origen, mientras su hijo, con el que emprendió el peligroso periplo desde Centroamérica, sigue en Estados Unidos. Y advierte que algunas pruebas de ADN no han sido concluyentes, disponible en: www.elpais.es, julio 7 de 2018. 
santuario y uno de los estados con más migración, no se quedó sin pronunciarse. $^{48}$

Un fallo judicial de 1997 de gran calado y significado —ratificado después por otras sentencias-, conocido como Acuerdo Flores, estableció que ningún niño puede permanecer en un centro de detención más de 20 días aunque esté con sus padres. ${ }^{49}$ Con la nueva política de separación de los menores, este límite ya no afectaba a sus progenitores. La orden ejecutiva mencionada, firmada el 20 de junio 2018, instó al fiscal general a solicitar

48 El Gobierno intentó, a través de una demanda, acabar con la ley santuario en el estado de California, la que permite que ninguna agencia policial del estado pueda colaborar con la policía de inmigración federal. Sin embargo, el juez federal de Sacramento, John Méndez, respaldó dos de las tres normas que protegen a los indocumentados, dándole una victoria a California contra la administración federal.

Este triunfo al ataque legislativo de Trump es de un enorme simbolismo. California, donde se calcula que vive una cuarta parte de los 11 millones de indocumentados del país, fue el primer estado santuario, y al que el fiscal general, Jeff Sessions, quien suele hacer citas bíblicas cuando defiende las políticas migratorias como la tolerancia cero, le ha declarado la guerra por sus medidas protectoras con los inmigrantes ilegales. La decisión de Méndez deja intacta la política de que las agencias policiales locales y estatales tengan prohibido indagar el estatus migratorio de las personas, colaborar en los operativos de la agencia de Inmigración y Control de Aduanas (ICE) y transferir a los detenidos por faltas menores.

No obstante, el juez aclaró que no se puede multar a dueños de empresas o fábricas con 10,000 dólares por permitir la entrada de ICE o porque accedan a los documentos migratorios de los empleados. Disponible en: www.elpais.es, julio 7 de 2018.

49 El acuerdo toma su nombre por Jenny Lisette Flores, una niña de 15 años de El Salvador. Huyó de su país en 1985 e intentó ingresar a los Estados Unidos para estar con su tía. El INS la arrestó en la frontera y la colocaron en un centro de detención juvenil, donde fue esposada y registrada, según la Marquette Law Review. El INS se negó a otorgarle a su tía la custodia de Jenny porque no entregaría menores a "adultos terceros”, según el artículo de revisión de la ley. La Unión Estadounidense de Libertades Civiles presentó una demanda colectiva en nombre de la niña y otros menores, lo que finalmente condujo al acuerdo Flores durante la administración Clinton.

Durante años, las personas criticaron al INS, diciendo que no había implementado completamente las regulaciones establecidas por el acuerdo Flores, según el informe del Servicio de Investigación del Congreso.

Cinco años después del acuerdo, la Ley de Seguridad Nacional de 2002 dividió las responsabilidades de procesar y cuidar a los niños inmigrantes. Sin embargo, preocupaba que no se cumplieran las regulaciones. En 2008, el Congreso aprobó la Ley de Reautorización de Protección de Víctimas de Tráfico de William Wilberforce.

En 2015, la juez federal de distrito, Dolly Gee, dictaminó que los requisitos de Flores se aplican tanto a menores no acompañados como a niños detenidos con sus padres, lo que significa que todos los menores deben ser liberados de la detención si es posible. 
la marcha atrás de ese acuerdo y el plazo, planteando acelerar los procesos judiciales para las familias, e instó al Departamento de Defensa a facilitar instalaciones para albergarlas.

Aun con precedentes como el Acuerdo Flores, la realidad perpetúa inconsistencias, así, por su oportunidad, creemos que es interesante delinear ciertas "particularidades" que derivan del estatus de nacionalidad de los hijos menores de padres deportados, y de esta manera podemos considerar:

a) Hijos ciudadanos o nacidos en los Estados Unidos de padres deportados (US citizen children of deported parents), quienes, en su interés superior, son puestos bajo custodia después de la deportación de un padre para ser reunificado con ese padre en su país de origen, los cuales obtienen evaluaciones integrales del padre, o cuidador potencial en otro país, así como una evaluación de los recursos disponibles que le dan para su ubicación, que es un paso crucial en la toma de decisiones.

b) Hijos no nacidos o ciudadanos en los Estados Unidos de padres deportados (non-US citizen children of deported parents), los cuales son retenidos después de la detención o deportación de un padre, corriendo un riesgo mayor porque no están sujetos a los mismos derechos y servicios que los niños nacidos en Estados Unidos; específicamente, niños que les tocó sufrir la política de "tolerancia cero" y no sólo se les separa, sino que son procesados como menores no acompañados y deben ser entregados al cuidado de un hogar de acogida temporal o a un hogar temporal de la Office of Refugee Resetlement (ORR) dentro de los 20 días y mientras se espera el proceso de deportación, lo que puede llevar varios años debido a los atrasos actuales.

c) Menores no acompañados (unaccompanied minor children), los cuales, en su mayoría, no reciben un ajuste del estado migratorio y, como resultado, miles de menores indocumentados en los Estados Unidos están sujetos a la aplicación de la ley de inmigración con riesgo de detención y deportación. ${ }^{50}$

50 ISS, Developing Sustainable Repatriation and Reintegration Programs for Children and Families Separated by Borders, julio de 2018, p. 3.

Reiteramos el comentario vertido en páginas anteriores en torno a la propuesta de un mediador intercultural para esta minoridad desamparada, bajo la idea de que no basta ya con un abogado, tutor o guardián, tal y como se tiene contemplado, sobre el papel solo, hasta la fecha, sino una figura que pueda tener no solamente la formación específica, sino el respaldo de 
Pero la situación no queda en los acontecimientos tan lamentables acontecidos en 2018. La segunda quincena de agosto de 2019 presentó aún más desafíos para los migrantes en los Estados Unidos. El presidente Trump anunció, el 21 de agosto de ese año, una nueva regulación que permitiría detener a las familias migrantes más allá del límite de 20 días para retener a los niños. Los funcionarios de la administración Trump expresaron que la medida tiene como objetivo evitar que las familias abusen de una ley, digamos, permisiva, pues saben que si ingresan a los Estados Unidos con niños, serán liberados antes. La decisión reemplazaría el mencionado Acuerdo Flores ${ }^{51}$ que no sólo limita el tiempo de detención de un menor a los ya establecidos 20 días, sino que también describe los estándares mínimos de atención para inmigrantes en centros de detención. ${ }^{52}$

las autoridades involucradas que haga una efectiva protección integral e internacional de los menores migrantes no acompañados. González Martín, Nuria, "Vulnerable Migrants...”, cit.

51 El Acuerdo Flores v. Reno de 1997 ha aparecido en los titulares recientemente, ya que el gobierno de los Estados Unidos ha criticado la separación de los niños inmigrantes de sus padres. El acuerdo limita el periodo de tiempo y las condiciones bajo las cuales los funcionarios estadounidenses pueden detener a niños inmigrantes.

El lunes 19 de agosto de 2019, un juez federal en California rechazó el intento del Departamento de Justicia de modificar el acuerdo al solicitar más tiempo para detener a los niños que los 20 días que actualmente se permiten. La administración Trump solicita que los niños sean retenidos con sus padres en las instalaciones de Inmigración y Control de Aduanas, en lugar de las instalaciones autorizadas requeridas por el acuerdo.

También requiere que los funcionarios de inmigración den a los menores detenidos una cierta calidad de vida, que incluye alimentos, agua potable, asistencia médica en emergencias, baños, lavabos, control de temperatura, supervisión y tanta separación de adultos no relacionados como sea posible, según un Informe del Servicio de Investigación del Congreso.

Durante la década de 1980, la antigua agencia gubernamental Servicio de Inmigración y Naturalización, fue acusada de maltratar a niños inmigrantes, según el informe del Servicio de Investigación del Congreso, lo que resultó en una serie de demandas que dieron lugar al acuerdo de conciliación de Flores.

52 Hablando de estándares mínimos de atención, la Aduana y Protección Fronteriza de los Estados Unidos confirmó que no vacunará a los migrantes detenidos contra la gripe. El 20 de mayo de 2019 un menor guatemalteco de 16 años, Carlos Gregorio Hernández Vásquez, murió en la celda de una estación de la patrulla fronteriza en Welasco, Texas, enfermo de influenza. Allí permaneció seis días en cuarentena, en lugar de ser llevado al hospital. La falta de control sanitario se evidencia en éste y en los cinco niños fallecidos desde diciembre de 2018 a diciembre 2019 después de haber sido detenidos por las autoridades estadounidenses. Disponible en: https: / / www.cnn.com/2019/05/20/politics/migrant-child-diesin-government-custody $/$ index.html?utm_source $=C N N+$ Five + Things\&utm_campaign $=b b 46 c 950 c 8$ - 
Esta revista forma parte del acervo de la Biblioteca Jurídica Virtual del Instituto de Investigaciones Jurídicas de la UNAM

De esta manera, igualmente, tenemos que, a finales de agosto de 2019, aumentaron las declaraciones controvertidas por parte del presidente estadounidense. Éste expresó que estaba considerando "seriamente" la posibilidad de poner fin a la ciudadanía estadounidense por derecho de nacimiento, a pesar de que tal medida enfrentaría un desafío legal inmediato, manifestándose en absoluto desacuerdo con el precedente de la Suprema Corte y el texto de la Decimocuarta Enmienda constitucional - aunque es cierto que ésta no es la primera vez que el presidente Trump ha hablado sobre terminar el proceso por el cual los nacidos en el país se convierten automáticamente en ciudadanos- $-{ }^{53}$ La capacidad de un presidente para poner fin a la ciudadanía por derecho de nacimiento ha sido ampliamente cuestionada por una variedad de legisladores y académicos.

El número de familias y niños detenidos en la frontera sur de Estados Unidos, en los últimos tiempos, ha sido realmente ascendente. Hasta septiembre de 2019 más de 430,000 miembros de familias migrantes han sido arrestados por cruzar la frontera ilegalmente, en comparación con alrededor de 100,000 durante todo el año anterior. ${ }^{54}$ El aumento se debe, en parte, al incremento de solicitantes de asilo. Por otro lado, Estados Unidos continúa en vías de no admitir refugiados en el país; el Departamento de Estado, en particular desde los últimos meses de 2019, ha estado retrasando sistemáticamente la admisión de refugiados. La administración Trump ha propuesto limitar el número de refugiados permitidos en los Estados Unidos, el próximo año fiscal, en 18,000, un mínimo histórico. Pero hasta que el presidente firme el límite, no se admitirán nuevos refugiados. Ello refleja todo el movimiento en torno a la solicitud de Estados Unidos a México para ser "tercer país seguro". ${ }^{55}$

EMAIL_CAMPAIGN_2019_12_05_07_44\&utm_medium=email\&utm_term=0_6da287d761bb46c950c8-100712849 (fecha de consulta: 6 de diciembre de 2019).

53 Disponible en: https: / /www.cnn.com/2019/08/21/politics/trump-birthright-citizenship-1 4th-amendment $/$ index.html?utm_source $=C N N+$ Five + Things\&utm_campaign $=e 1$ ee 921 e 21 EMAIL_CAMPAIGN_2019_08_22_04_56_COPY_O1\&utm_medium=email\&utm_ term $=0 \_6 d a 287 d 761-e 1 e e 921 e 21-100712849$.

54 La administración Trump planea derivar fondos, destinados para casos de desastre (unos 155 millones de dólares) de la Federal Emergency Management Agency, para apoyar la política de retorno de los migrantes a México. Disponible en: https: //www.cnn. com/2019/10/29/politics.

55 Brooks, David, op. cit., p. 10. Estados Unidos asegura que todavía discute con México un acuerdo de tercer país seguro para solicitantes de asilo, a pesar de que el gobierno mexicano 
En el mismo sentido, la administración Trump estaría cerca de cerrar un acuerdo con Guatemala que limitaría quién es elegible para el asilo en los Estados Unidos. Según el acuerdo, Guatemala actuaría como un "tercer país seguro" y se comprometería a ofrecer asilo a los migrantes que lo soliciten. La ley de Estados Unidos permite a los migrantes solicitar asilo una vez que llegan a territorio estadounidense, pero existe una advertencia si los migrantes viajan a través de países que se consideran seguros según los acuerdos con los Estados Unidos (Canadá también es uno de ellos desde 2002). El acuerdo con Guatemala es parte de los esfuerzos de la administración para frenar el número de solicitantes de asilo, y en virtud del mismo, los que ya estén en el país podrían ser enviados a Guatemala. Los defensores de inmigrantes sostienen que este tipo de acuerdos ponen a los migrantes en peligro y traicionan el compromiso de los Estados Unidos de proteger a las poblaciones vulnerables. En síntesis, el acuerdo es parte de un esfuerzo concertado de la administración para frenar el flujo de solicitantes de asilo a los Estados Unidos. ${ }^{56}$

Una vez que el acuerdo esté implementado y la logística se haya confirmado, Estados Unidos comenzará a transferir algunos migrantes que buscan asilo a Guatemala para buscar protección allí. Pero hay algunas excepciones, como problemas médicos y niños no acompañados. ${ }^{57}$ Así, en noviembre de 2019 el gobierno de Donald Trump inició deportaciones bajo su nuevo con-

reitera que eso es inaceptable. Las autoridades norteamericanas confirman que más de 42 mil solicitantes de asilo no mexicanos fueron devueltos con el programa Permanecer en México (su nombre formal es Protocolos de Protección de Migrantes, MPP, por sus siglas en inglés). Después de que Trump amenazara a México con imponer aranceles si no frenaba el creciente flujo de migrantes, se negoció un acuerdo bilateral en junio que incluía el despliegue de la recién formada Guardia Nacional en puntos fronterizos como la ampliación del plan Permanecer en México a toda la frontera por donde Estados Unidos obligaba a solicitantes de asilo (no mexicanos) a esperar la resolución de sus casos. Véase, asimismo, Ortega Velázquez, Elisa, ¿México como tercer país (in)seguro? El asilo como derecho humano en disputa, México, UNAM, Instituto de Investigaciones Jurídicas, 2020, Opiniones Técnicas sobre Temas de Relevancia Nacional, núm. 13, disponible en: https: //www.juridicas.unam.mx/publicaciones/ detalle-publicacion/150.

56 Alvarez, Priscilla y Sands, Geneva, "US Close to Implementing Asylum Agreement with Guatemala”, CNN Politics, octubre 23 de 2019, disponible en: https: / / www.cnn.com/20 19/10/23/politics/us-asylum-agreement-guatemala.

57 No hay datos certeros del número de migrantes que Guatemala aceptará y cuántos estarán sujetos a transferencia; incluso el acuerdo aún está pendiente de firma, al igual que su posterior vigencia. Por otra parte, la Agencia de las Naciones Unidas para los Refugiados 
Esta revista forma parte del acervo de la Biblioteca Jurídica Virtual del Instituto de Investigaciones Jurídicas de la UNAM

venio de asilo de "tercer país seguro" con Guatemala. Esencialmente, como expresamos, el acuerdo permite a los Estados Unidos rechazar a los solicitantes de asilo legítimos y redirigirlos a otro país aprobado para presentar su caso. Hasta ahora parece que sólo una persona ha sido deportada bajo el nuevo sistema, entonces pareciera que el programa se está implementando de manera "gradual". 58

El pacto con Guatemala fue el primero de una serie de acuerdos similares con países centroamericanos. En el año fiscal 2019, Aduanas y Protección Fronteriza detuvieron y consideraron inadmisible a casi un millón de personas, la mayoría de los cuales eran de países de Centroamérica: Guatemala, El Salvador y Honduras.

Al revisar el ligamen de la protección debida, internacional e integral, una vez más, a la comunidad relativa a la minoridad que cruza fronteras, en esta ocasión referida a los acontecimientos iniciados en abril de 2018 en la frontera norte de México y los Estados Unidos al separar a los hijos de sus padres y/o cuidadores, ${ }^{59}$ vemos que hay un deber de enfrentar la realidad, y que es responsabilidad del gobierno proteger a las familias vulnerables sin importar si permanecen en Estados Unidos o si se ven obligadas a irse. ${ }^{60}$ Es responsabilidad de cada país proteger a los niños donde sea que estén, independientemente de su origen. ${ }^{61}$ Se deben implementar en la legislación disposiciones sólidas, bajo un modelo colaborativo y coordinado, para iden-

define "país seguro", en parte, como "países en los que los refugiados pueden disfrutar del asilo sin ningún peligro”.

58 Disponible en: https://www.cnn.com/2019/11/21/politics/guatemala-asylum-agreement/ index.html?utm_source $=C N N+$ Five + Things\&utm_campaign $=a c 4 a b 0 b c 3 f-E M A I L \_$ CAMPAIGN_2019_11_22_03_04\&utm_medium=email\&utm_term=0_6da287d761ac4ab0bc3f-100712849 (fecha de consulta: 22 de noviembre de 2019).

59 Hacemos notar, en este momento, el hecho de la amplia crítica por parte de una doctrina mayoritaria hacia las deficiencias en el sistema legal de los Estados Unidos cuando se trata de los derechos de los niños ciudadanos del país a ser cuidados por sus padres inmigrantes no documentados. Véase Hall, C. E., "Where Are My Children... and my Rights? Parental Rights Termination as a Consequence of Deportation”, Duke Law Journal, vol. 60, 2011, pp. 1459 y ss.

60 ISS, Developing Sustainable Repatriation and Reintegration Programs for Children and Families Separated by Borders, julio de 2018, p. 4, disponible en: http://cimmcw.org/wp-con tent/uploads/ISS-Practice-Brief.pdf.

61 Hablamos de la protección de los derechos humanos — que las leyes nacionales e internacionales les reconocen - y de los obstáculos para dicha garantía, en los que se incluyen la ausencia de perspectiva de niñez en la aplicación de la normativa en materia de migración, 
Esta revista forma parte del acervo de la Biblioteca Jurídica Virtual del Instituto de Investigaciones Jurídicas de la UNAM

tificar, apoyar y reintegrar a los niños vulnerables. ${ }^{62}$ No queremos menores migrantes que encuentren un camino más traumático que el que dejaron atrás en sus países de origen. ${ }^{63}$

En este caso puntual, familias que buscan cruzar fronteras, es notorio que las políticas nor teamericanas tienen la tendencia de socavar, pareciera que sistemáticamente, derechos humanos de su población migrante.

\section{CONCLUSIONES}

Definitvamente, el panorama migratorio ha ido cambiando, en el tiempo y en el espacio, y con relación a la minoridad no acompañada, las familias y el contexto México y Estados Unidos, el cambio es más que patente. ${ }^{64}$

la carencia de garantías básicas de debido proceso y de un enfoque que considere su calidad de menores en los procedimientos migratorios, entre otros.

62 ISS, Children on the Move. From Protection towards a Quality Sustainable Solution. A Practical Guide, disponible en: http://iss-blog.iss-usa.org/ (próximamente en español también). La importancia de este magnífico manual es fundamental ante la ausencia de una verdadera estructura de actuación transfronteriza, ni desde la norma ni desde la práctica. El valor del manual, junto con su difusión, es crucial; véase tan sólo cómo se invita a los abogados a que se involucran en dichos temas representando a los menores, que actúen como tales y no como trabajadores sociales o case managers, los cuales ya realizan su tarea. Coordinación y colaboración entre los diferentes interlocutores y no incursión en áreas que no les corresponden.

63 A las razones por las que dejaron sus países: guerras, violencia doméstica, pobreza, cambio climático y sequía (que agravan dichos niveles de pobreza), víctimas de tráfico, persecución religiosa, forzados a contraer matrimonio, desastres naturales, reagrupación familiar e incluso mejores oportunidades de estudio o de trabajo, entre otras, se unen los riesgos que van implícitos en este movimiento o migración: detención, explotación sexual, explotación laboral, reclutamiento de pandillas, abuso y violencia, malnutrición, adicciones, muerte o daños serios, entre otros. Situaciones que llegan a ser, en muchos casos, de mayor dimensión que aquellas de las que huyeron de sus países de origen.

Para un panorama en torno al tema en general véase Unicef, A Child is a Child. Protecting Children on the Move from Violence, Abuse and Explotation, Nueva York, Unicef, 2017; Unicef, Broken Dreams. Central American Children's Dangerous Journey to the United States, Ginebra, Unicef, 2016.

64 Disponible en: https: / / travel.state.gov/content/travel/en/legal/visa-lawO/vis-statitics/noni mmigrant-visa-statistics.html. "Total Illegal Alien Apprehensions by Month", disponible en: www.cbp.gov/sites/default/files/assets/documents/2019-Mar/bp-total-monthly-apps-sector-areafy2018.pdf (fecha de consulta: 28 de agosto de 2019); Patrulla Fronteriza de Estados Unidos, 
Esta revista forma parte del acervo de la Biblioteca Jurídica Virtual del Instituto de Investigaciones Jurídicas de la UNAM

La migración forzada, no tanto de trabajadores temporales que se trasladan solos, sino de migrantes mujeres, familias completas y menores no acompañados marcan la diferencia; ya no es una migración económica, es una migración que huye de fenómenos violentos muy variados, una migración que llega para quedarse, en donde la movilidad de mexicanos se une a la migración centroamericana y de otros contextos, como el haitiano, el cubano o el venezolano, entre otros.

México, derivado de lo anterior, se constituye no sólo en país de tránsito y origen, sino también de destino. Las últimas cuatro oleadas de caravanas, desde octubre de 2018 a enero de 2020, han sido testigo de ello: 1) una primera caravana que inicia en el territorio de origen de los migrantes - como una primera característica- en este caso en Honduras, y continúa por Tapachula, Chiapas, en octubre 2018 (se conceden solicitudes de refugiados); 2) como respuesta a esta primera oleada, y aumentando en volumen —una segunda característica — , se constituye la siguiente caravana en enero 2019 (se conceden visas humanitarias masivas); 3) una tercera caravana a finales de abril de 2019, con una presencia aún mayor de mujeres, niños, niñas y jóvenes - tercera característica- (se conceden visas de visitante transfronterizo por siete días), y 4) una última caravana, enero de 2020, en donde la cobertura de los medios de comunicación sigue tomando un papel relevante desde la primera caravana - constituyendo una cuarta característica- (los migrantes traen consigo oficios de apatridia, en 20 días tienen que salir del país). La participación de una variedad significativa de interlocutores hacen, además, de estas oleadas de caravanas una diferencia tal, donde migrantes y deportados, organizaciones no gubernamentales y gubernamentales, medios de comunicación, entre otros, marcan y hacen visible la crisis humanitaria migratoria forjada por políticas de cerrazón.

Si las caravanas no era el objeto de este trabajo, las circunstancias de actualidad las traen a colación, y vemos que junto a ellas, la migración ha transitado por numerosos trazos que, lamentablemente, se reiteran, desde la empatía y

“Total Family Unit Apprehensions by Month", disponible en: www.cbp.gov/sites/default/files/ assets/documents / 2019-Mar/bp-total-monthly-family-units-sector-fy13-fy18.pdf (fecha de consulta: 28 de agosto de 2019); Patrulla Fronteriza de Estados Unidos, "Total Unaccompanied Alien Children (0-17) Apprehensions by Month”, disponible en: www.cbp.gov/sites/default/files/ assets/documents /2019-Mar/bp-total-monthly-uacs-sector-fy2010-fy2018.pdf (fecha de consulta: 28 de agosto de 2019); CBP, "Southwest Border Migration FY 2019", disponible en: www.cbp. gov/newsroom/stats/sw-border-migration, actualizado el 9 de septiembre de 2019. 
la tolerancia con rasgos de xenofobia hasta la contención y detección militarizada, donde se vislumbra un escenario desolador y más que preocupante.

Lo que impacta en la frontera sur repercute en la frontera norte, y así, por ejemplo, en Tijuana y Baja California, en 2020, hay una migración de la denominada histórica: junto con el migrante retornado o expatriado, el migrante interno y aquellos migrantes que desean ingresar bajo el Protocolo de Protección a la Población Migrante (Migrant Protection Protocols, MPP, por sus siglas en inglés, o también denominados Remain in Mexico Policy), que cubre a aquella población migrante no mexicana - centroamericanos, básicamente- de entre 18 y 60 años de edad, de habla hispana y que ingresa a través de la frontera sur de México; que sufre un "proceso", pareciera sin fin y sin solución positiva, en donde migrantes irregulares y solicitantes de asilo deben esperan en México sus resoluciones. De 56,000 solicitudes bajo el MPP, 24,000 se resolvieron, y sólo un $1 \%$ tuvo respuesta positiva, ${ }^{65}$ todo ello sin mencionar el lapso transcurrido desde que se inició este programa o la vulnerabilidad en la que se encuentran los migrantes ante la visibilidad que les dan a los cárteles, con los consecuentes secuestros, asesinatos, extorsiones o tráfico de personas. La vulnerabilidad en su máxima potencia, una vez más.

Un solicitante de asilo, en una entrevista, expresó que los cárteles pueden decir quién acaba de regresar de los Estados Unidos después de sus trámites, por sus zapatos sin cordones y las carpetas color manila y documentos que llevan consigo. Alrededor de 60,000 migrantes han sido devueltos a México bajo esta política de "Permanecer en México" de la Administración Trump, que requiere que los solicitantes de asilo esperen fuera de las fronteras de Estados Unidos mientras se procesan sus casos, ${ }^{66}$ como una alternativa para la no separación de familias o una forma de reducir la sobrepoblación en los centros de detención, pero lo que en definitiva logra, y es su fin principal, es contener esta población migratoria solicitante de asilo.

65 Gandini, Luciana y Fernández de la Reguera, Alethia, "Exposición de investigación y experiencia sobre el fenómeno y la crisis migratoria actual”, invitadas en la Agenda de Deliberación Institucional que tuvo lugar el día 13 de febrero de 2020, en la sala Guillermo Florís Margadant del Instituto de Investigaciones Jurídicas de la UNAM.

66 Disponible en: https://www.cnn.com/2019/12/01/world/mexico-asylum-seekers-letters/in

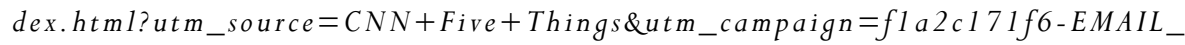
CAMPAIGN_2019_12_02_02_32\&utm_medium=email\&utm_term=0_6da287d761fla2c171f6-100712849. 
La situación de las familias y menores no acompañados descrita en estas páginas se une a la evidencia que detona la mencionada última caravana de enero de 2020, ya que ésta marca una diferencia con respecto a las pasadas; desde el número de migrantes, la "modalidad" de migrante, la grave situación de Honduras, el mandato de Donald Trump, la creciente animadversión en México en cuanto a la recepción de migrantes, el desbordamiento de las autoridades, la tibia respuesta de la Comisión Nacional de Derechos Humanos en México, como muestra de una situación que incide, directamente, en la frontera norte con un pronóstico no muy esperanzador.

Si bien esta es la realidad, la práctica que se da rutinariamente, no nos anclamos en la solicitud que la teoría nos lanza en relación con nuestra minoridad más vulnerable; es decir, los Estados están obligados, bajo el principio de no discriminación, a respetar y garantizar los derechos de la Convención sobre los Derechos del Niño a

...todas las infancias ocultas tras la nomenclatura de niñez migrante, independientemente de que se les considere migrantes en situación regular o irregular, niños de la calle, solicitantes de asilo, refugiados, apátridas y/o víctimas de trata, incluso en situaciones de retorno o deportación al país de origen, independientemente de la nacionalidad del niño o de los padres o tutores legales, la condición migratoria o la apatridia. ${ }^{67}$

La primacía de los derechos del niño en el contexto de migración internacional debe ser aplicada por los Estados e incorporar el marco jurídico internacional de la niñez migrante a sus políticas, a sus prácticas y a todas las medidas adoptadas por éstos. ${ }^{68}$

67 Los principios generales relativos a los derechos humanos de los niños en el contexto de la migración internacional, y las obligaciones de los Estados relativas a los derechos humanos de los niños en el contexto de la migración internacional en los países de origen, tránsito, destino y retorno, son definidos en las observaciones generales núm. 22 y núm. 23 del Comité de los Derechos del Niño de las Naciones Unidas. Committee on the Protection of the Rights of All Migrant Workers and Members of Their Families. Committee on the Rights of the Child, Joint General Comment No. 3 (2017) of the Committee on the Protection of the Rights of All Migrant Workers and Members of Their Families and No. 22 (2017) of the Committee on the Rights of the Child on the General Principles Regarding the Human Rights of Children in the Context of International Migration, 2017, p. 3. Citado por Serrano Sánchez, Lucia, op. cit.

68 Committee on the Protection of the Rights of all Migrant Workers and Members of their Families. Committee on the Rights of the Child, Joint General Comment No. 3 of the 
Nos negamos a pensar que todo queda por escrito y nada se aterriza en la práctica. Por ello somos defensores a ultranza de esta lucha tan necesaria como urgente, si bien, conscientes de lo que el mensaje enviado expresa claramente, en donde pareciera que los objetivos están volcados no sólo hacia un ataque político, sino hacia un ataque al ser humano per se; es decir, la intención de desmoralizar, vencer al migrante para que abandone su lucha por sus derechos. Y así es, lo vemos desde la política de "tolerancia cero"; la separación familiar; incluso la velada intención antimigratoria de la Declaración Conjunta México-Estados Unidos, con los aumentos arancelarios para las exportaciones de productos mexicanos; la medida o limitación de solicitudes de asilo en un puerto de entrada "Port of Entry"; el denominado Acuerdo de Cooperación de Asilo (Asylum Cooperation Agreement, ACA, por sus siglas en inglés) $;{ }^{69}$ el protocolo para "Permanecer en México" (MPP) $;{ }^{70}$ los acuerdos de "tercer país seguro" que no son más que otra argucia por parte de los Estados de destino para disminuir el número de solicitantes de asilo en sus territorios, evadiendo su obligación de protección internacional y derivándola a otro Estado, el cual, y lo sabemos todos, no puede hacer frente, con las consecuencias lamentables que ello conlleva.

Ahora, en momentos de pandemia de covid-19 en este 2020 que pasó, parece que el tiempo se detiene; los inmigrantes ya no son el peligro realmente importante o, al menos, el más inminente, porque la vida es primero y el resto puede esperar. Pero esto no es así, hay que seguir protegiendo a los más vulnerables porque los compromisos internacionales siguen vigen-

Committee on the Protection of the Rights of All Migrant Workers and Members of Their Families.

69 Se debe solicitar asilo en uno de los países a los que viajó antes de solicitar asilo en los Estados Unidos; destinado a centroamericanos, se aplica a los solicitantes de asilo que llegaron a la frontera sur antes del 16 de julio de 2019 y está justificado por la sección 208 (a) (2) (A) del INA. En cuanto a este proceso, iniciado en 2016 y en el que se limita la cantidad de personas que pueden solicitar asilo en una entrada de puerto cada día, véase Al otro lado v.Wolf, presentado en noviembre de 2017. El 19 de noviembre de 2019 aquellos que estaban en la metering list (lista de medición) antes del 16 de julio de 2019, cuando la Transit Ban entró en vigor, están protegidos por la misma prohibición de tránsito. El Centro Robert Strauss de la Universidad de Texas realiza y circula informes de medición trimestrales.

70 Subrayamos los esfuerzos de apoyo para personas sujetas a MPP, tales como talleres profesionales con la organización no gubernamental "Al otro lado", en Tijuana, Baja California, o la "Court Observation”, como ocurre en San Antonio, para observar las audiencias en carpas en Laredo. 
tes. El primer principio del Conjunto de Principios para la Protección de Todas las Personas Sometidas a Cualquier Forma de Detención o Prisión, emitido por la Asamblea General de la Organización de Naciones Unidas en la Resolución 43/173, de 9 de diciembre de 1988, establece que toda persona sometida a cualquier forma de detección o prisión será tratada humanamente y con el respeto debido a la dignidad inherente al ser humano, así como a los preceptos de la propia Ley de Migración mexicana, artículos 107 y 109, que indican que los extranjeros presentados ante el Instituto $\mathrm{Na}$ cional de Migración tienen el derecho de permanecer en un espacio digno y sano hasta que se resuelva su situación migratoria.

Asimismo, se advierte la necesidad de adoptar medidas cautelares en todas las instalaciones que alberguen personas en contexto de migración; es decir, evitar hechos violatorios que afecten la salud, la integridad, la seguridad y la vida de las personas alojadas en ellas, entre las que se encuentran niñas, niños, adolescentes, mujeres y personas adultas mayores. Y como hablamos del covid-19 y su propagación, se incluyen las medidas necesarias que protejan igualmente al personal que labora en las propias instalaciones y visitas en general, donde se incluyen organizaciones civiles, entre otras.

Vayamos más lejos aún, ante el cierre de fronteras, a los migrantes detenidos en los centros - y a los extranjeros varados en territorio mexicanocon el fin de garantizar sus derechos fundamentales, se les debe gestionar los acuerdos internacionales que implementen mecanismos que faciliten la digna y sana repatriación de los mismos: México firmó, el 5 de mayo de 2006, el Memorándum de Entendimiento entre los Gobiernos de los Estados Unidos Mexicanos, de la República de El Salvador, de la República de Guatemala, de la República de Honduras y de la República de Nicaragua para la Repatriación Digna, Ordenada, Ágil y Segura de Nacionales Centroamericanos Migrantes Vía Terrestre. El valor de la vida de todos, migrantes dentro y fuera de las estaciones migratorias, no son la excepción.

\section{BIBLIOGRAFÍA}

AlvareZ, Priscilla y SANDS, Geneva, "US Close to Implementing Asylum Agreement with Guatemala”, CNN Politics, octubre 23 de 2019, dis- 
ponible en: https: / / www.cnn.com / 2019/10/23/politics/us-asylum-agree ment-guatemala.

Bustamante, Jorge, Migración internacional y derechos humanos, México, UNAM, 2002.

Caldwell, B., "Deported by Marriage. Americans Forced to Choose between Love and Country", Brook Law Review, vol. 82, 2016.

Collins, Kristin A., "Illegitimate Borders: ius sanguinis Citizenship and the Legal Construction of Family, Race, and Nation", The Yale Law Journal, vol. 123, núm. 7, mayo de 2014.

Douglas, G. et al. (eds.), International and National Perspectives on Child and Family Law. Essays in Honour of Nigel Lowe, Cambridge, Intersentia, 2018.

FERnÁNDEZ DE LA REgUERA, Alethia et al., "Caravanas migrantes: las respuestas de México”, México, UNAM, Instituto de Investigaciones Jurídicas, 2019, Opiniones Técnica sobre Temas de Relevancia Nacional, núm. 8, disponible en: https: / / biblio.juridicas.unam. $m_{x} /$ bjv/detallelibro / 584-caravanas-migrantes-las-respuestas-de-mexico-serie-opiniones-tec nicas-sobre-temas-de-relevancia-nacional-num- 8 .

Foster, C. H., “Anchor Babies and Welfare Queens: An Essay on Political Rhetoric, Gendered Racism, and Marginalization”, Women, Gender, and Families of Color, Estados Unidos, vol. 5, núm. 1, primavera de 2017.

GAUDEMENT-TALLON, H. "Individualisme et mondialisation: aspects de droit international privé de la famille", A Commitment to Private International Law. Essays in honour of Hans van Loon /Un engagement au service du Droit international privé. Mélanges en l'honneur de Hans van Loon, Cambridge-Amberes-Portland, Intersentia, 2013.

GONZÁlEZ MARTÍN, Nuria, "Apuntes desde el derecho internacional privado relacionados con los «niños dejados atrás»: especial consideración a los menores no acompañados y familias separadas", en Pérez Contreras, Montserrat y Macías y Pérez, Elisa (coords.), Derechos humanos, migración y desplazamiento forzado, México, UNAM, Instituto de Investigaciones Jurídicas, 2020.

GonzÁlez MarTín, Nuria, "Derecho de nacionalidad en los Estados Unidos de América”, en LARA, María Ángeles (coord.), Normativas de nacionalidad en derecho comparado, Granada, Tirant lo Blanch, 2020.

GONZÁLEZ MARTÍN, Nuria, "Globalización familiar: nuevas estructuras para su estudio", Libro Homenaje al Profesor Eugenio Hernández-Bretón, Caracas, Academia de Ciencias Políticas y Sociales, 2019, t. I. 
Esta revista forma parte del acervo de la Biblioteca Jurídica Virtual del Instituto de Investigaciones Jurídicas de la UNAM

GonZÁLEZ MARTín, Nuria, "Vulnerable Migrants: Mediation for Unaccompanied Minors in the Border between US/Mexico", Newsletter Weinstein International Foundation, 2020.

GonzÁlez Vicente, P., "Cuestiones internacionales en derecho de familia”, Homenaje a Luis Zarraluqui Sánchez-Eznarriaga. La voz del derecho de familia, Madrid, AEAFA, 2017.

Guzmán Zapater, Mónica y Esplugues Mota, Carlos (dirs.), Persona y familia en el nuevo modelo español de derecho internacional privado, Valencia, Tirant lo Blanch, 2017.

HACKER, D. , Legalized Families in the Era of Bordered Globalization, Cambridge University Press, 2017.

Hall, C. E., "Where Are My Children... and my Rights? Parental Rights Termination as a Consequence of Deportation", Duke Law Journal, vol. $60,2011$.

KIM, J. K. et al., "Genderacing Immigrant Subjects: «Anchor Babies» and the Politics of Birthright Citizenship”, Social Identities, vol. 24, núm. 3 mayo de 2018.

LAKOsIL, N., “The Flores Settlement: Ripping Families Apart under the Law", Golden Gate U. L. REv, vol. 48, 2018.

Lowe, N. y Douglas, G., Families across Frontiers, La Haya, Martinus Nijhoff, L, 1996.

MuIR WATT, Horatia, "Les modèles familiaux à l'épreuve de la modialisation (Aspects de Droit international privé)", en CAlvo CARAVACA, A. e IRIARTE, Ángel, J. (eds.), Mundialización y familia, Madrid, Colex, 2001.

NGAI, Mae M., "Birthright Citizenship and the Alien Citizen", Fordham Law Review, núm. 5, abril de 2007.

Ortega VelázQUEZ, Elisa, ¿México como tercer país (in)seguro? El asilo como derecho humano en disputa, México, UNAM, Instituto de Investigaciones Jurídicas, 2020, Opiniones Técnicas sobre Temas de Relevancia Nacional, núm. 13, disponible en: https: //www.juridicas.unam.mx/publicaciones /detalle-publicacion / 150 .

PRICE, Polly J., "Natural Law and Birthright Citizenship in Calvin's Case (1608)", Yale.

SERRANO SÁNCHEZ, Lucia, "Vulneraciones y acceso a los sistemas de protección de los derechos de la niñez y adolescencia migrante no acompañada en España y El Salvador”, tesis doctoral, Programa de Doctorado en Ciencias Jurídicas, Universidad de Granada, España, defensa: 9 de 
Esta revista forma parte del acervo de la Biblioteca Jurídica Virtual del Instituto de Investigaciones Jurídicas de la UNAM

julio de 2019, tesis inédita y premio a mejor tesis doctoral, Universidad Internacional de La Rábida.

SpIRO, P. J., Report on Citizenship Law: United States of America, EUDO Citizenship Observatory, julio de 2015, disponible en: https: / cadmus.eui.eu /bitstream/handle/1814/36498/EUDO_CIT_CR_2015_13_USA. pdf? sequence $=1$ \&isAllowei $=y$.

Tiffany, Joseph, "Anchor Babies and the Challenge of Birthright Citizenship”, Contemporary Sociology, vol. 47, núm. 6, noviembre de 2018.

Unicef, A Child is a Child. Protecting Children on the Move from Violence, Abuse and Explotation, Nueva York, Unicef, 2017.

Unicef, Broken Dreams. Central American Children's Dangerous Journey to the United States, Ginebra, Unicef, 2016. 